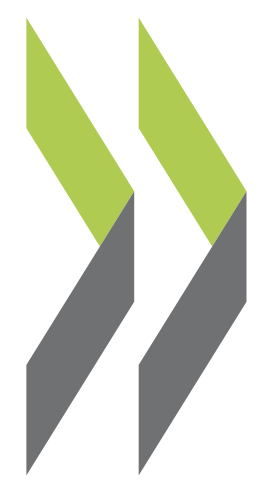

OECD Science, Technology and Industry Working Papers $2017 / 03$

Having the right mix: The role of skill bundles for comparative advantage and industry performance in GVCs

\section{Robert Grundke,}

Stéphanie Jamet,

Mariagrazia Squicciarini 


\section{OECD SCIENCE, TECHNOLOGY AND INDUSTRY WORKING PAPERS}

OECD Working Papers should not be reported as representing the official views of the OECD or of its member countries. The opinions expressed and arguments employed are those of the authors.

This document, as well as any data and map included herein, are without prejudice to the status of or sovereignty over any territory, to the delimitation of international frontiers and boundaries and to the name of any territory, city or area.

Working Papers describe preliminary results or research in progress by the author(s) and are published to stimulate discussion on a broad range of issues on which the OECD works. Comments on Working Papers are welcomed, and may be sent to OECD Directorate for Science, Technology and Innovation, OECD, 2 rue André-Pascal, 75775 Paris Cedex 16, France; e-mail: sti.contact@oecd.org.

The release of this working paper has been authorised by Andrew Wyckoff, OECD Director for Science, Technology and Innovation. 


\title{
HAVING THE RIGHT MIX: THE ROLE OF SKILL BUNDLES FOR COMPARATIVE ADVANTAGE AND INDUSTRY PERFORMANCE IN GVCS
}

\author{
Robert Grundke*, Stephanie Jamet ${ }^{+}$, Margarita Kalamova ${ }^{+}$, Mariagrazia Squicciarini*
}

\begin{abstract}
This study investigates the role of countries' overall skills endowment on their trade comparative advantage. It tests the theoretical model of Ohnsorge and Trefler (2007) who argue that it is the bundling of various skills at the worker level and their joint distribution that matter for industry and trade specialisation. This departs from the literature assuming that workers are endowed with only one type of skills, which are generally measured by educational attainment. To test the predictions of the model, this paper uses information on cognitive skills assessed within the OECD Survey of Adult Skills (PIAAC) and data from the OECD-WTO Trade in Value Added (TiVA) database. Results show that workers' skills bundles and their distribution have a larger effect on specialisation than countries' endowment of capital per employee or the relative endowment of workers possessing different levels of education. Furthermore, this study tests the model of Bombardini et al. (2012) for a large cross-section of countries and finds evidence that the within-country dispersion of skills significantly affects specialisation patterns.
\end{abstract}

Acknowledgements: The authors thank country delegates to the Working Party for Industry Analysis (WPIA) and the Committee for Innovation, Industry and Entrepreneurship (CIIE), the participants in the Skills Strategy Advisory Group (SSAG) as well as Sebastian Benz and seminar participants in Turin and Mannheim for helpful comments and suggestions. This work was completed while Robert Grundke was seconded as a Junior Professional Officer (JPO) at the OECD by the German Federal Government. 


\section{TABLE OF CONTENTS}

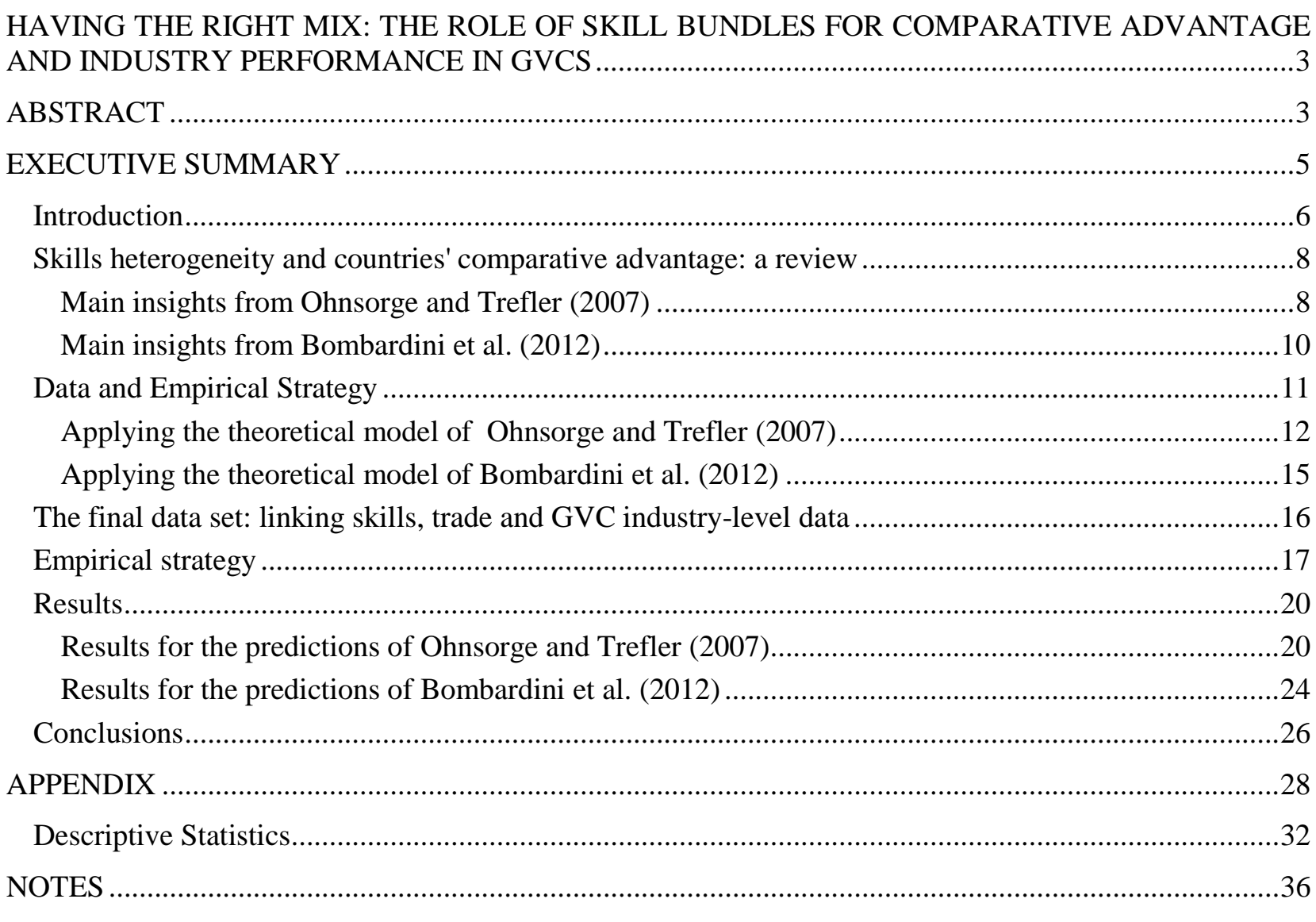

REFERENCES .39 


\section{EXECUTIVE SUMMARY}

This work contributes to the policy discussion on the role played by skills and skills' endowment for countries' industrial specialisation patterns and positioning in global value chains (GVCs). It is the result of joint work by the Directorate for Science, Technology and Innovation (STI) and the Directorate for Education and Skills (EDU).

The study relies on information on cognitive skills assessed within the OECD Survey of Adult Skills (PIAAC) and data from the Trade in Value Added (TiVA 2015) database. It further exploits novel taskbased skill indicators (detailed in Grundke et al., 2017), which allow measuring the extent to which industries differ in the workers' skills required for production (the so called 'skill intensity' of industries). The focus is on the intensity of industries in managerial, self-organisation ${ }^{1}$ and marketing and accounting skills.

This work addresses the questions of how the skill composition of a country's workforce (both type of skills and their distribution) shapes specialisation in specific industries as well as their competitiveness and integration into global value chains. It does so by testing the theoretical predictions of models that use measures of workers' heterogeneity to investigate the effects of skills on industry specialisation and international trade (Ohnsorge and Trefler, 2007; Bombardini et al., 2012). Key findings are:

- Industry competitiveness and positioning in GVCs depend on bundles of skills at the worker level, rather than on workers endowed with only one type of skills (e.g. problem solving skills). Policies focusing on enhancing only certain types of skills may thus end up being counterproductive for overall industry competitiveness. For instance, quantitative or STEM (Science, Technology, Engineering and Mathematics)-related skills need to be complemented with communication and team-working skills for ICT industries to thrive.

- Workers' observed heterogeneity in their skills' mix (i.e. their bundles of skills), as well as country-wide dispersion of skills, matter for countries' specialisation in specific industries and the extent to which these industries integrate into global markets. For instance, two countries characterised by similar average levels of "literacy skills" may end up specialising in completely different industries and position themselves at different stages along GVCs depending on the "skills dispersion" underlying the observed mean levels.

- The distribution of workers' skills matters for industry competitiveness and positioning in GVCs both when skills are taken individually (by type of skills), as well as when they are taken in bundles.

- The magnitude of the implied trade effects of the distribution of skills' bundles is larger than the trade effects predicted by the relative endowment of capital to labour, which shows that skills are key for economies to thrive in GVCs.

Taken together, the results suggest that education and skills policies as well migration policies, which are sometimes thought to be only remotely connected to industry and trade policies, strongly influence countries' industrial structure and specialisation in international trade, as they shape within countries' skills distributions. Better coordination and alignment of industrial and trade policies with educational policies are thus needed to avoid counteracting policies and inefficiencies. Having the 'right' bundle of skills at the worker level emerges as an imperative for sectors to be competitive along GVCs. 


\section{HAVING THE RIGHT MIX: THE ROLE OF SKILL BUNDLES FOR COMPARATIVE ADVANTAGE AND INDUSTRY PERFORMANCE IN GVCS}

\section{Introduction}

The performance and positioning of firms, as well as the specialisation and competitiveness of industries and economies in global value chains (GVCs) are shaped by the skill composition of the workforce. Studies in the international trade literature provide important insights about the way in which skills, and more broadly human capital, shape comparative advantages in GVCs. Heckscher-Ohlin general equilibrium models (see e.g. Heckscher and Ohlin, 1991, for an overview), which predict the patterns of commerce and production based on the factor endowments of countries and regions, argue that countries (regions) will specialise in and export products which use their relatively more abundant and cheap factor(s) of production more intensively. Countries (regions) will conversely import products using their relatively scarcer factor(s).

In such types of frameworks, a relatively skilled workforce - with skills measured by educational attainment - has been recognised as a source of comparative advantage enabling countries to specialise in high-skilled activities (Romalis 2004, Chor 2010). In these models, workers are generally thought to either be unskilled or skilled - that is, skill endowment is measured in a dichotomous fashion - and only the country-level relative endowment of each worker type matters for countries' comparative advantage and specialisation in international trade. The focus has mainly been on individually considered types of skills only, whereas common knowledge suggests that workers are heterogeneous in terms of the (bundles of) skills they are endowed with and that different skills and combinations thereof may matter jointly.

Addressing these concerns, recent theoretical literature has introduced other types of workers' heterogeneity to investigate the effects of skills and human capital on the patterns of industry specialisation and international trade (Grossmann 2013). On the one hand, Grossman and Maggi (2000), Grossman (2004), Bougheas and Riezman (2007) and Bombardini et al. (2009) investigate the effects of the country wide dispersion of human capital on countries' comparative advantage, with endowment still measured in terms of one single skill. On the other hand, Ohnsorge and Trefler (2007) focus on the importance of a mix of various skills at the worker level (the "skill bundle") and on their country-wide joint distribution for countries' comparative advantage in international markets.

While theory has been advancing in this respect, the empirical literature investigating the effect of workers' heterogeneity, in terms of both skill types and skill distribution, on countries' comparative advantage in GVCs remains nevertheless fairly scant (Bombardini et al. 2012, Assuyama 2012). Among the few studies that exist, OECD exploratory analysis (Grundke et al., 2016) suggests that various types of skills and different moments of the skill distributions of countries relate to economic performance and trade in value added patterns in different ways.

This work contributes to the policy discussion on the role of skills and skill endowment for countries' industrial specialisation patterns and positioning in GVCs and advances the existing literature on comparative advantage in several ways.

First, it tests the predictions of the theoretical model of Ohnsorge and Trefler (2007) about the effect of workers' skills mix (skill bundle) and the country-wide distribution of these skill bundles on trade specialisation. Ohnsorge and Trefler (2007) assume that workers possess more than one skill, with skills that are bundled at the worker level; and that firms in different industries search for workers with a certain 
combination of skills (i.e. the skill bundle). Their model predicts that the country wide distribution of skill bundles affects the specialisation of countries' in certain industries and their integration in international markets and GVCs. This study finds strong evidence for this prediction and shows that skill bundles matter much more than traditional determinants of countries' comparative advantage: the magnitude of the implied trade effects of the skill bundle distribution are larger than the effects of the relative endowment of capital to labour as well as the relative endowment of workers with different levels of education. In addition, this work also finds evidence in support of Bombardini et al.'s (2012) empirical results that the within-country dispersion of skills matters for industry specialisation. This implies that two countries featuring similar average skill endowment levels may end up specialising in completely different industries and position themselves at different production stages along GVCs depending on the skills' dispersion underlying the observed mean levels.

Second, the present analysis uses information on assessed numeracy, literacy and problem solving skills from the OECD Survey of Adult Skills (PIAAC) ${ }^{2}$ to measure the cognitive skills that workers are endowed with. This is an important contribution, as previous studies only rely on educational attainment to proxy for workers skills (Romalis 2004, Chor 2010; the only exception is Bombardini et al. 2012). Moreover, this study exploits novel task-based skill indicators, which were constructed using information on job tasks from PIAAC, to measure the skill intensity of industries (see Grundke et al., 2017 for details). The novel task-based skill indicators not only mirror the different types of cognitive skills that workers are endowed with, but also manage to account for the intensity of managerial, self-organisation and marketing and accounting tasks of industries. This represents an important step towards a better understanding of the type of skills that matter for economic performance and for GVCs, as previous studies only rely on educational attainment and dichotomous occupational classifications (i.e. production vs. non-production workers) to measure skill intensities of industries (Romalis 2004, Chor 2010). This analysis further relies on value-added indicators from the Trade in Value Added Database (TiVA 2015), ${ }^{3}$ which make it possible to better account for the sequential and fragmented nature of worldwide production processes, and to get more accurate and realistic measures of GVCs.

Third, to the best of our knowledge, this study is the first to propose an analysis encompassing agricultural, manufacturing and services industries and to use average industry intensity measures computed across a larger number of countries. Existing studies mainly focus on manufacturing industries only and rely on United States industry-related measures, which are then used as if they were representative for all countries.

Taken together, the results obtained call for the need to coordinate industrial policies and education and skills policies, for countries to preserve and enhance their comparative advantages. They further underline the importance of having the "right" skill mix at the worker level, for production and industrial specialisation purposes, and that policies focusing only on certain types of skills may be short-sighted. Quantitative or STEM (Science, Technology, Engineering and Mathematics)-related skills need to be complemented with communication and team working skills. While it is true that firms in e.g. information and communication technologies-related industries or in manufacturing industries may need workers with strong quantitative skills, it is also true that these workers will not be able to adequately participate in the production process if lacking a certain level of communication and team-working skills. Education and skills policies, which are sometimes thought to be only remotely connected to industrial and trade policies, appear to strongly influence countries' industrial structure and specialisation in international trade, as they shape within countries' skills distributions. Thus, a better coordination and alignment of industrial and trade policies with education and skills policies seems to be necessary to avoid counteracting effects of policies on industries and trade patterns that cause inefficiencies. 
The remainder of this paper first reviews the literature on the links between countries' skills distribution and comparative advantages. It then develops the hypotheses that are empirically tested and proposes a number of specifications aimed at assessing the effect of different moments of the skills distributions and of bundles of skills on the comparative advantage of countries. A discussion of what the empirical evidence provided suggests as well as of possible alleys for future policy-relevant research concludes the paper.

\section{Skills heterogeneity and countries' comparative advantage: a review}

Existing empirical studies suggest countries' comparative advantages in certain industries and their specialisation in international trade to arise out of, among others: relative factor endowments (Davis and Weinstein 2001, Romalis 2004, Egger et al. 2011), international technology differences (Trefler 1993 and 1995, Eaton and Khortum 2002, Morrow 2010), institutional quality (Levshenko 2007, Nunn 2007, Costinot 2009), labour market frictions (Cuñat and Melitz 2010, Tang 2012), the capacity to comply with product standards (Essaji 2008), credit constraints (Manova 2008) and trust (Cingano and Pinotti 2016).

In this literature, skills and human capital appear as determinants of countries' comparative advantage mainly in the context of relative factor endowments (Romalis 2004, Chor 2010). As mentioned, skill endowment is measured by educational attainment and workers are thought of being either unskilled or skilled. Comparative advantage and specialisation in international trade are shaped by the relative total endowment of each worker type at the country level. Costinot (2009) deviates from this Heckscher-Ohlintype of analysis and postulates that the level of human capital per worker matters only in conjunction with countries' institutional quality. He further argues that it is only the average level of one type of human capital per worker that matters for countries' specialisation in international trade. Conversely, differences in human capital between workers, as captured by moments of the distribution of human capital other than the mean, as well as different types of human capital do not matter.

The theoretical literature on the determinants of countries' comparative advantage has only recently introduced types of workers' heterogeneity other than the typical Heckscher-Ohlin dichotomy of unskilled vs. skilled workers. On the one hand, Grossman and Maggi (2000), Grossman (2004), Bougheas and Riezman (2007) and Bombardini et al. (2009) investigate the effects of the country wide dispersion of human capital, which is assumed to be a single skill, on countries' comparative advantage. They predict that even if countries have the same average skill endowments, differences in the dispersions of skills will lead to industry specialisation and trade between those countries. On the other hand, Ohnsorge and Trefler (2007) deviate from the assumption that workers only possess one type of skills and focus on the importance of a mix of various skills at the worker level (skill bundles). They predict that, in addition to the typical Heckscher-Ohlin effect of relative skill endowments, the country specific joint distribution of the various skills bundled at the worker level strongly influences the comparative advantage of countries and their specialisation in international trade.

While theory has been advancing, only few studies provide relevant empirical evidence. Among them there are Bombardini et al. (2012) and Assuyama (2012). These have shown that the country wide dispersion of skills affects industrial specialisation and the integration of countries in international markets: countries with higher skill dispersion specialise in industries featuring lower skill complementarities (Bombardini et al. 2012) or having shorter production chains (Assuyama 2012).

\section{Main insights from Ohnsorge and Trefler (2007)}

The theoretical model of Ohnsorge and Trefler (2007) focuses on a new mechanism to explain why countries' skills endowments matter for the specialisation in certain industries and in international markets. The authors argue that it is especially the mix of skills at the worker level (skill bundle) that matters for the 
production process, rather than having heterogeneous types of workers each endowed with a single skill. As an example, they refer to a survey of the Indian ICT sector showing that employers look for workers endowed with specific bundles of skills. They highlight that, while many graduates from Indian engineering schools are endowed with the needed quantitative skills, they nevertheless lack important teamwork and presentation skills, and therefore do not meet the industry's requirements for employability.

Ohnsorge and Trefler (2007) show that the joint distribution of skill bundles within a country's population influences the specialisation of countries within specific industries as well as countries' specialisation in international trade. Their model features two types of skills, namely 'quantitative skills' and 'communication and teamwork skills'. The authors show that different moments of the joint distribution of these two skills within the working population of countries, i.e. the correlation of skills across individuals, the joint variance of these skills and their relative mean, affect the comparative advantage of countries and their specialisation in international trade.

The model makes the following assumptions: workers are heterogeneous and endowed with two attributes, i.e. a specific bundle of quantitative and communication skills ${ }^{4}$; industries differ according to their relative skill requirements ${ }^{5}$; the marginal product of a specific skill bundle differs across industries; and industries pay workers a wage equal to their marginal product. ${ }^{6}$ Workers sort across industries on the basis of Ricardian comparative advantages, i.e. they sort into the industry that pays the most for the specific skill bundle they possess. Thus, although workers are perfectly mobile across industries, each worker is endogenously specific to the industry where his specific skill bundle has the highest marginal product.

Hence, the allocation of workers across industries is not determined by how much of each attribute a worker is endowed with, but rather by how these attributes are bundled together, i.e. by the ratio of the skill levels per worker. Ohnsorge and Trefler (2007) call this ratio the 'comparative advantage of workers' for specific industries. For example, a worker with a high ratio of quantitative to communication skills has a comparative advantage in quantitative industries and will sort into these industries accordingly. While the absolute level of skills does not influence the sorting of workers across industries, it affects the absolute productivity of workers and hence their wages. Thus, workers with high levels of both skills have an absolute advantage in all industries. Given the ratio of quantitative to communication skills for a certain worker, the higher the level of communication skills of this worker, the higher her quantitative skills.

The authors call the ratio of both skills the relative comparative advantage and the level of the communication skills, given the ratio of both skills, the absolute advantage of workers. ${ }^{7}$ One key parameter explaining countries' specialisation in certain industries is $\rho$, i.e. the country wide correlation between comparative and absolute advantage across workers. For instance, in the case of a comparative advantage measured as the ratio of quantitative to communication skills, and of an absolute advantage measured as communication skills, a positive correlation of comparative and absolute advantage means that workers sorting into quantitative-intensive industries (because they have a comparative advantage in those industries) are also the workers having an absolute advantage in all industries. Conversely, workers sorting into communication intensive industries are the ones with an absolute disadvantage in all industries. The reverse is true for a negative $\rho$. If $\rho$ is close to zero, workers with an absolute advantage in all industries are dispersed randomly across quantitative and communication-intensive industries.

Ohnsorge and Trefler (2007) predict that in a hypothetical two country world where trade is balanced, no barriers to trade exist and countries do not differ in any aspect except for differences in $\rho$ (i.e. countries have the same relative factor endowments, preferences and production functions as well as the same mean and standard deviation of the joint distribution of quantitative and communication skills), the country with the higher $\rho$ will specialise in industries that are relatively intensive in quantitative skills, for example ICT industries. This will happen as the best workers, i.e. those having an absolute advantage in both skills, will 
sort into the quantitative intensive industry and will thus increase the absolute productivity of this industry compared to other countries with a lower correlation. Conversely, the country with the lower $\rho$ will specialise in communication intensive industries, such as the movie industries.

To illustrate their theoretical predictions, the authors rely on data from the International Adult Literacy Survey (IALS, i.e. an antecedent of the OECD's PIAAC) and compute some basic moments of the joint distributions of skills for the countries in the sample. In particular, they interpret assessed literacy skills as measuring contextual understanding and communication skills and assessed numeracy as quantitative skills. Analysing the correlations of comparative advantage and of absolute advantage across workers within countries, they conclude that there are significant differences across countries, but do not elaborate further on this empirical evidence. ${ }^{8}$

Ohnsorge and Trefler (2007) further develop two more predictions on how the joint distribution of workers' skill bundles matters for the specialisation of countries in international markets. The first one states that if two countries differ only with respect to the variance of the joint skill distribution of quantitative and communication skills (with mean and $\rho$ being the same in both countries), the country with the higher joint variance will specialise in industries that are intensive either in quantitative or in communication skills. The country with the smaller variance will conversely specialise in industries that are neither intensive in quantitative nor in communication skills. As an example, the authors put forward the case of Germany and argue that the country's narrow joint distribution in those skills might explain why Germany is a major exporter of manufactured goods requiring both types of skills to a similar extent (i.e. they are not intensive in any of them). Conversely, the United States, with their highly unequal joint distribution of skills, specialise in industries that are intensive in either quantitative skills (e.g. ICT) or industries that are intensive in communication skills, like the movie industry.

Ohnsorge and Trefler's (2007) third prediction is similar to the Heckscher-Ohlin prediction adapted to two types of skilled labour. It states that the country that is relatively more endowed with quantitative relative to communication skills will specialise in quantitative-intensive industries. The country that is relatively less endowed with quantitative skills will specialise in communication intensive industries. In their model, the relative skill endowment is expressed as the population mean of the ratio of quantitative to communication skills per worker. A country with a higher average ratio of quantitative to communication skills per worker will have relatively more workers with a skill bundle that yields them a comparative advantage in quantitative intensive industries. Thus, for this country it will be relatively cheaper to produce quantitative intensive products than communication intensive products, as compared to a country with a lower average ratio. The country with the higher ratio will therefore export relatively more quantitative intensive products.

\section{Main insights from Bombardini et al. (2012)}

Most of the existing literature studying the relationship between worker heterogeneity and international trade generally overlooks the existence of frictions in the labour market (Grossmann 2013). Studies generally assume that firms can readily observe the abilities of workers that they might potentially hire. However, empirical evidence shows that labour markets are plagued with frictions that impede an efficient matching of workers to industries, firms and production teams (e.g. Krishna et al. 2012).

Bombardini et al. (2009, 2012 and 2014) model and empirically investigate the dynamics of a multicountry, multi-industry model of trade in which firms are unable to perfectly observe the ability levels of their potential hires. In their model, production requires teams of workers and industries differ in the extent to which employees' talent within the production team is complementary or substitutable. Some industries, such as aerospace or engine manufacturing, require completing long sequences of tasks. Poor performance at any single stage greatly reduces the value of output. These industries, known as the O-ring model 
(Kremer, 1993), have high skills complementarity (low skill substitutability case) and efficiency improves when workers of similar skills are employed in every stage of the production. In other industries, such as paper manufacturing, skills are more easily substitutable (low skill complementarity case) and poor performance in some tasks can be mitigated by superior performance in others, implying that, for instance, teamwork is relatively less important.

The authors assume a search environment such that firms in every industry sample randomly from the country's unobserved talent distribution. As a consequence, perfect matching of workers with similar ability levels is not possible and efficient sorting of abilities to industries is not obtained. These random matches are particularly costly (in terms of expected output) in industries where the complementarities between workers' talents are greatest. In a setting with many countries and many goods, the authors predict that a country with a relatively smaller dispersion of unobserved ability levels will export goods characterised by greater complementarities in the production processes.

When testing their model, Bombardini et al. (2012) use data from the International Adult Literacy Survey (IALS) to measure countries' unobserved skill dispersions. The data on literacy skills from the IALS reveals substantial cross-country differences in the skill dispersion for the 19 countries considered. The authors approximate the distribution of unobserved skills (so-called 'residual skills') by purging IALS scores for literacy of the effect of a variety of observable characteristics, such as education, age (measured in terms of 5 age groups), gender, immigrant status and participation in adult education or training programmes in the 12 months prior to the survey date.

As the degree of skill complementarity in production is not directly observable, Bombardini et al. (2012) take two distinct approaches. First, they use the distribution of residual wages within industries obtained by means of purging the effects of observable characteristics from observed wages - to proxy for the unobserved degree of skill complementarity of an industry. Based on their theoretical model, they argue that industries with a higher complementarity of skills have a more compressed residual wage distribution. To compute the residual wage distribution within industries, they use U.S. Census data and assume that the industry ranking of the degree of complementarity of skills does not change across countries. Second, they use a set of proxies to account for the skill complementarity of industries built on data from O*NET, the occupational network database published by the U.S. Department of Labor ${ }^{9}$. These allow quantifying the degree of teamwork, communication and interdependence between workers' labour inputs, for a variety of industries. Bombardini et al. (2012) argue that industries with a higher degree of team work and communication will show a relatively higher degree of skill complementarity in production. For their empirical specification, they use the ranking of industries on the complementarity index for the U.S. as proxy for the general ranking of industries across countries.

Bombardini et al. (2012) show that countries with narrower unobserved skill dispersion specialise in sectors characterised by higher complementarity of skills across tasks, i.e. sectors where teamwork is crucial and efficiency is higher if workers of similar skills are employed at every stage of production (such as aerospace or engine manufacturing).

\section{Data and Empirical Strategy}

This study uses OECD PIAAC data to investigate the importance of the mix of different types of skills and their joint distribution for the industrial structure and the specialisation of countries in international trade and tests the theoretical prediction of Ohnsorge and Trefler (2007). It also extends the empirical analysis of Bombardini et al. (2012) to a larger set of cognitive skills and a larger sample of countries. PIAAC provides a unique possibility to better measure different types of skills as well as their use in specific industries. Hence, while existing literature has mainly relied on educational attainment to 
proxy skills, this paper relies on the cognitive skills measured by PIAAC as well as the new task-based skill measures described in Grundke et al. (2017).

\section{Applying the theoretical model of Ohnsorge and Trefler (2007)}

Regarding the empirical test of Ohnsorge and Trefler's (2007) model, this study uses the assessed cognitive skills literacy, numeracy and problem solving to measure the skill bundles that workers are endowed with. It seems reasonable to assume that a country's supply of assessed cognitive skills of its adult population (as measured by PIAAC) is exogenous to countries specialisation in international trade and GVCs. The empirical implementation proposed exploits all possible combinations of skills, namely: numeracy and literacy, problem solving and numeracy and problem solving and literacy.

The relative intensity of industries in these three types of skills is computed using new indicators of job-specific skill and task requirements constructed using items included in the PIAAC background questionnaire (see Grundke et al., 2017). ${ }^{10}$ For the analysis it is important to establish a correspondence between assessed cognitive skills and the new indicators on job-related skill requirements. This can be done using PIAAC, as one of the declared purposes of the survey was to measure the use of assessed cognitive skills as well as of other skills at the work place (OECD, 2013, p. 20). ${ }^{11}$

Table 1. Indicators on job-related task and skill requirements

\begin{tabular}{|c|c|c|}
\hline $\begin{array}{l}\text { Indicator on job } \\
\text { related skill } \\
\text { requirements }\end{array}$ & Items included in the construction of the indicator & $\begin{array}{l}\text { Correspondence with } \\
\text { assessed cognitive skill }\end{array}$ \\
\hline $\begin{array}{l}\text { Managing and } \\
\text { Communication }\end{array}$ & $\begin{array}{c}\text { F_Q02c Frequency of giving speeches and presentations } \\
\text { F_Q03b Frequency of planning activities of others } \\
\text { F_Q02b Frequency of instructing and teaching people } \\
\text { F_Q02e Frequency of advising people } \\
\text { F_Q04a Frequency of persuading or influencing others }\end{array}$ & Literacy \\
\hline $\begin{array}{l}\text { Marketing and } \\
\text { Accounting }\end{array}$ & $\begin{array}{l}\text { G_Q01g Frequency of reading financial invoices, bills etc. } \\
\text { G_Q03b Frequency of calculating prices, costs, budget } \\
\text { G_Q03d Frequency of using calculator } \\
\text { F_Q02d Frequency of client interaction selling a product or a } \\
\text { service }\end{array}$ & Numeracy \\
\hline Self-Organisation & $\begin{array}{l}\text { D_Q11a extent of own planning of the task sequences } \\
\text { D_Q11b extent of own planning of style of work } \\
\text { D_Q11c extent of own planning of speed of work } \\
\text { D_Q11d extent of own planning of working hours }\end{array}$ & Problem Solving \\
\hline
\end{tabular}

Note: The indicators on job-related skill requirements are constructed using an exploratory factor analysis and a set of 57 items from the PIAAC background questionnaire (for further details see Grundke et al., 2017).

Source: Grundke et al., 2017

Based on the description of the cognitive assessment tests contained in the technical report of PIAAC (OECD 2013), it is reasonable to assume that assessed literacy does not just measure the common notion of literacy, intended as simple reading and writing of texts. Literacy is defined in PIAAC as: "understanding, evaluating, using and engaging with written texts to participate in society, to achieve one's goals, and to develop one's knowledge and potential" (ibid., Chapter 2, p. 3). The literacy test hence tries to get insights about three broad cognitive strategies, two of which relate to interpretation, reflection and the evaluation of tasks. Participants were required to relate parts of one text to parts of other texts and to draw on knowledge, ideas and values external to the text to evaluate aspects of the text and understand the broader context. Thus, in a spirit similar to Ohnsorge and Trefler's (2007) and Bombardini et al.'s (2012), and their interpretation of assessed literacy in the IALS, the assessed literacy skills contained in PIAAC can be interpreted as also measuring the ability to analyse complex social contexts and to deal with social interaction using the language, an ability which is strongly related to communication and interaction skills. 
This study therefore relates the measured concept of literacy to the tasked based skill indicator on Management and Communication (see Grundke et al., 2017).

Assessed numeracy is defined in PIAAC as "the ability to access, use, interpret and communicate mathematical information and ideas, in order to engage in and manage the mathematical demands of a range of situations in adult life" (ibid., Chapter 3, p. 6). Thus, PIAAC assessed numeracy mainly measures individuals' numerical abilities and the extent to which individuals can process mathematical information. Contextual interpretation of social communication is not a core concept measured by numeracy. Interpretation and reflection tasks exclusively focus on the analysis and interpretation of mathematical content including data and probability, dimension and shape, patterns and relationships and quantity and changes represented in the form of graphs and tables. Thus, assessed numeracy should be strongly related to the job requirements of complex and less complex numerical skills. This study argues that assessed numeracy is maximally related to the task based skill indicator Marketing and Accounting, which captures mainly less complex numerical tasks (see Grundke et al., 2017).

In PIAAC, the assessed skill "problem solving in technology-rich environments (PSTRE)" is defined as "using digital technology, communication tools and networks to acquire and evaluate information, communicate with others and perform practical tasks" (ibid. p. 9). However, the report states that “...the cognitive dimensions of problem solving were considered the central object of the assessment, with the use of ICT as secondary” (ibid. p. 12). The assessed cognitive dimensions include mental structures and processes involved when a person solves a problem, i.e. setting goals and monitoring progress, planning, accessing and evaluating information as well as making use of information by selecting, organising and transforming information (ibid. p. 10). Thus, the construct PSTRE substantially differs from the cognitive processes involved in the constructs literacy and numeracy. The assessed skill PSTRE also measures the ability to work in a self-organised and independent fashion, to identify problems, set goals and find solutions. Thus, it seems reasonable to relate this assessed skill PSTRE to the task based skill indicator of self-organisation and planning identified in see Grundke et al., 2017.

As mentioned, this study uses three types of cognitive skills (literacy, numeracy and problem solving) and their corresponding industry task intensity (Management and Communication, Marketing and Accounting and Self-Organisation) to empirically test the model of Ohnsorge and Trefler (2007). Because the model only focuses on skill bundles consisting of two different skills, this study tests the theoretical predictions of the model for each possible combination of two assessed cognitive skills (i.e. numeracy and literacy, problem solving and numeracy and problem solving and literacy) with their respective corresponding relative industry task intensity (i.e. Marketing and Accounting with Management and Communication, Self-Organisation with Marketing and Accounting, and Problem solving with Management and Communication).

Following Ohnsorge and Trefler (2007), a country's specific correlation of relative and absolute advantage of workers $(\rho)$ is computed as the correlation of the (log of the) ratio of two cognitive skills and the (log of the) skill in the denominator across all individuals within one country using PIAAC scores on cognitive skills. ${ }^{12}$ This correlation is computed for all three possible combinations of the assessed cognitive skills (numeracy, literacy and problem solving). For example, using the two assessed skills numeracy and literacy, the authors compute the correlation of the (log of the) ratio of numeracy scores to literacy scores with the (log of the) literacy scores. Figure 1 shows that the correlations differ substantially between countries for all three possible combinations of assessed cognitive skills. Taking the example of the correlation for numeracy and literacy, the figure shows a positive correlation of 0.26 for the United States and a negative correlation of -.021 for Estonia. This means that in the United States, workers with a relative comparative advantage in numeracy skills (high ratio of numeracy to literacy scores) are also the ones with higher absolute scores in both cognitive skills, i.e. numeracy and literacy. In contrast in Estonia, 
workers with a comparative advantage in numeracy skills have low absolute scores in both numeracy and literacy skills.

Figure 1: Correlation of relative and absolute cognitive skill advantage of workers, 2011

By country, for all three combinations of assessed cognitive skills

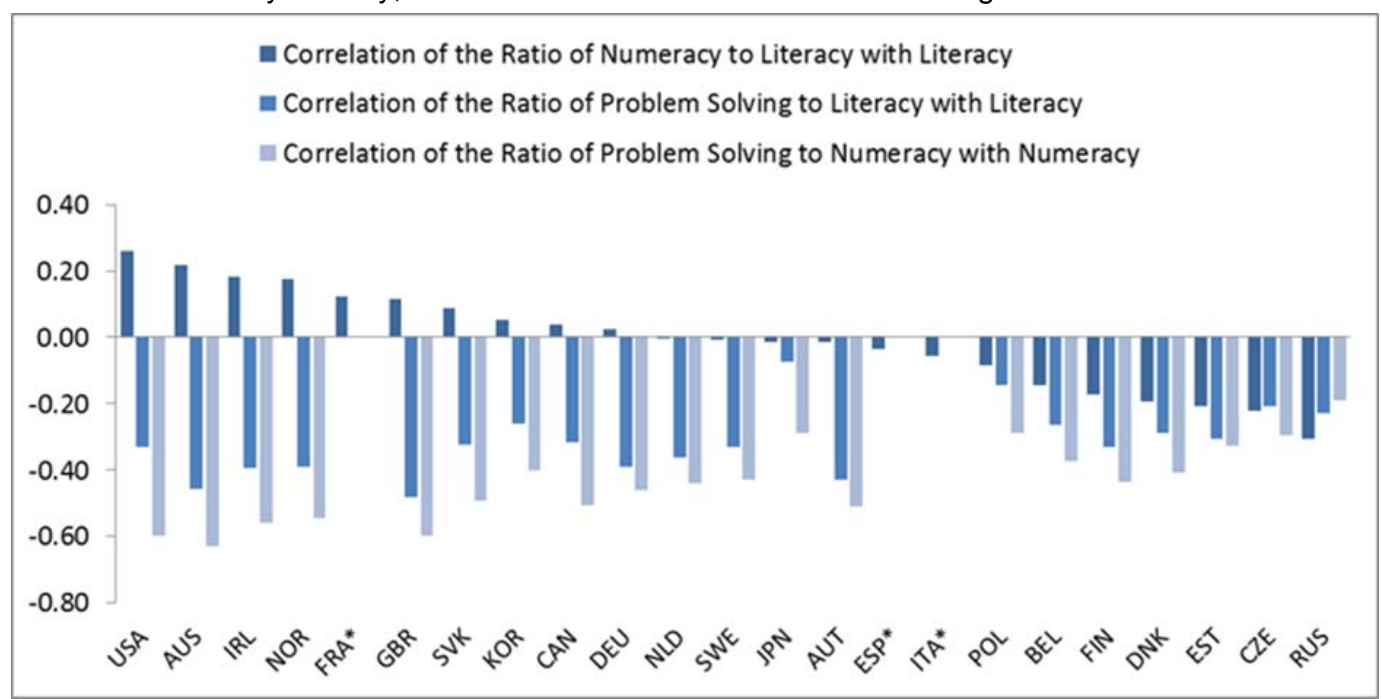

Source: Authors' own compilation on data from PIAAC.

Note: Asterisks $\left(^{*}\right)$ denote countries where problem solving in technology rich environments tests were not performed (OECD, 2013).

To test the prediction of Ohnsorge and Trefler (2007) on the effects of relative skill endowments on specialisation patterns, we compute the country-specific average relative endowment of workers with two cognitive skills (e.g. problem solving and numeracy) as the average of the (log of the) ratio of the two cognitive skills across all individuals within one country. To this end, PIAAC scores on cognitive skills are used. ${ }^{13}$ Figure 2 shows this relative endowment measure for all three combinations of cognitive skills, for all countries. Due to the use of logs of the ratio, a negative value of the relative endowment measure signals that the average ratio is smaller than 1 . In the case of problem solving and numeracy, the United States shows a strongly positive value of 0.06 , which means that workers in the USA are on average relatively better endowed with problem solving skills than with numeracy skills. For Slovakia, the same endowment measure is negative, which shows that workers in Slovakia are relatively better endowed with numeracy skills compared to problem solving skills. 
Figure 2: Relative endowment of cognitive skills by country

Log values, for all three combinations of assessed cognitive skills

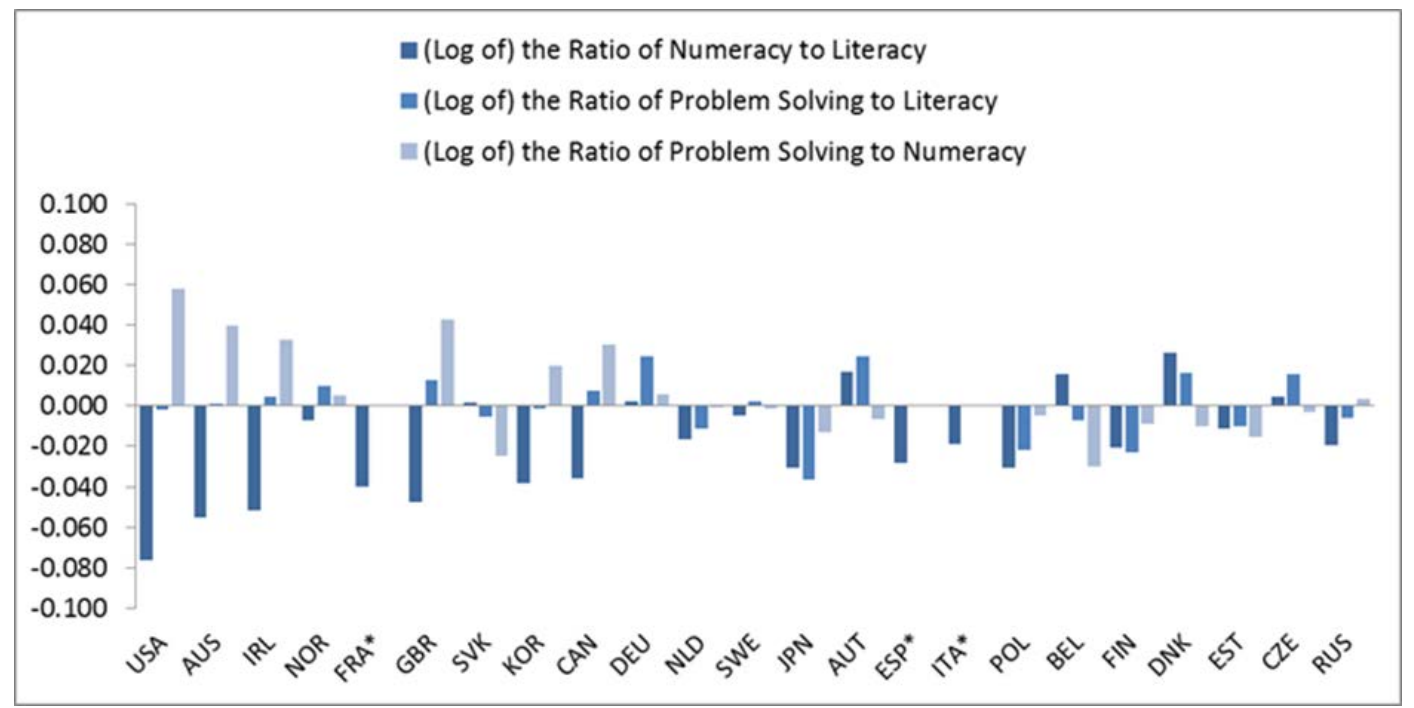

Source: Authors' own compilation on data from PIAAC.

Note: Asterisks $\left.{ }^{*}\right)$ denote countries where problem solving in technology rich environments tests were not performed (OECD, 2013).

The relative intensity of an industry in task-based skill A to task-based skill B is calculated as the average value of the task-based skill indicator A in the industry (across countries and individuals) divided by the average value of the task-based skill indicator $\mathrm{B}$ in the industry (across countries and individuals). ${ }^{14},{ }^{15}$ For example, when using problem solving and numeracy to compute countries' skill endowments, we compute the relative intensity of industries as the average value of the Self-organisation indicator by industry (calculated across all countries and individuals), divided by the average value of the Marketing and Accounting indicator by industry (also calculated across countries and individuals). In line with previous research on comparative advantage (Chor 2010, Bombardini et al. 2012), the authors construct an index that ranks industries according to the computed relative task intensity and use this index in the baseline specifications (Appendix Table A5). ${ }^{16}$ For example, the Finance and Insurance Industry (industry 24) is relatively less intensive in Self-Organisation as compared to Management and Communication as well as in Self-Organisation as compared to Marketing and Accounting (Column 1-2 and 3-4 of Table A5). Moreover, it is relatively intensive in Marketing and Accounting as compared to Management and Communication (column 5-6).

\section{Applying the theoretical model of Bombardini et al. (2012)}

To empirically test the theoretical predictions of Bombardini et al. (2012), this study relies on information about the three assessed cognitive skills included in PIAAC (i.e. literacy, numeracy and problem solving) to measure the unobserved skill dispersions of countries. Background information from PIAAC on individual characteristics such as education, age, gender, immigrant status and participation in adult education or training programmes, is used to 'purge' the skill distribution from observable characteristics (i.e. to get to the 'other things been equal' stage) and to compute the dispersion of unobserved skills, i.e. the residual skill distribution. Figure 3 shows the residual skill dispersion for the three cognitive skills. Across all countries, the residual dispersion of the problem solving skills is smaller or equal than the residual dispersion of numeracy and literacy skills. Japan has the lowest residual skill dispersions and Spain and Australia among others have the highest residual skill dispersions. 
Figure 3: Residual standard deviation of cognitive skills by country

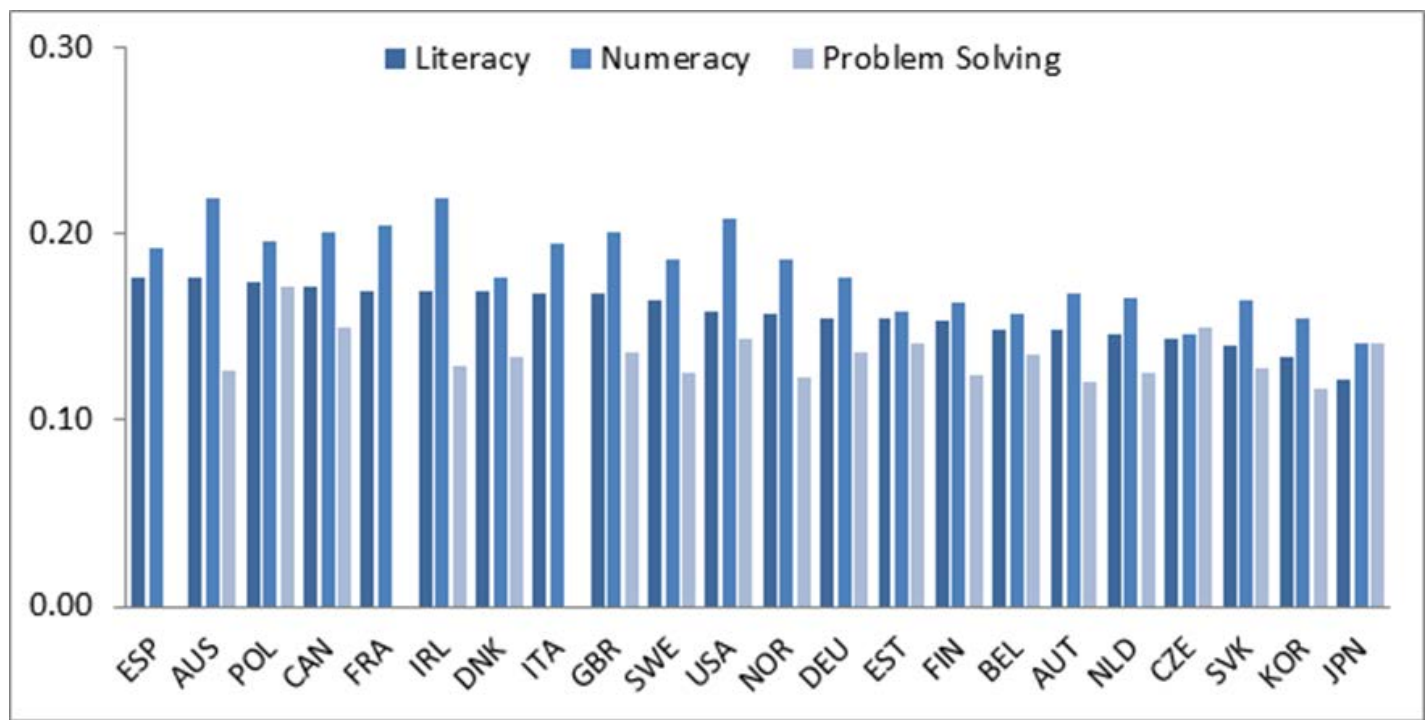

Source: Authors' own compilation on data from PIAAC.

The complementarity of production in industries is measured by the task-based skill indicator of Management and Communication, as this is similar to the O*NET measures used by Bombardini et al. (2012). As in Bombardini et al. (2012), an index ranking industries according to the computed complementarity index is constructed (see Table A6 Appendix). The industry Agriculture, Hunting, Forestry and Fishing is the industry that is the least intensive in Management and Communication and thus has the lowest skill complementarity in production. Production in this industry seemingly does not entail long chains of different tasks, and skills appear highly substitutable in production. The reverse is true for the Finance and Insurance Industry as well as other Services Sectors, which all rank high in the Management and Communication Indicator and thus show high levels of skill complementarity in production.

\section{The final data set: linking skills, trade and GVC industry-level data}

The analysis relies on a typical sectoral gravity model for bilateral trade flows, commonly used in the empirical literature on comparative advantage (Davis and Weinstein 2001, Romalis 2004, Nunn 2007, Levshenko 2007, Chor 2010). In this context, PIAAC data on skills have been linked to TiVA data for the year 2011 (i.e. the year for which PIAAC data are available) to generate a cross-sectional dataset on skills and trade flows in gross and value added terms. An important contribution of this study is in fact the use of value added trade flows as the dependent variable (Timmer et al. 2013). This allows avoiding problems of previous studies: as they rely on gross trade flows, they do not measure the actual value added created in the exporting country; and services are often excluded from estimations mainly focussing on manufacturing industries (Johnson 2014). To allow for comparisons with existing literature, the model is nevertheless also estimated using gross exports as the dependent variable.

The constructed bilateral industry level dataset includes: 23 exporting countries (excluding Cyprus ${ }^{1718}$ ) i.e. those countries for which skill-related PIAAC data are available; 61 importing countries; and 34 TiVA industries ${ }^{19}$ for the year 2011. Exports in gross and value added terms, domestic value added embedded in foreign final demand as well as final demand per importing countries' industry for the year 2011 are taken from the TiVA 2015 database. Measures for the distribution of cognitive skills within countries are computed using the assessment scores from the PIAAC database for the year 2011. The relative skill intensities of industries are measured using the task-based skill indicators described in 
Grundke et al., 2017, which use information from PIAAC on the tasks that workers perform on the job (see Table 1 above).

Additional control variables traditionally used in empirical analysis of comparative advantage (see Bombardini et al. 2012) have been included using fixed net assets data from the OECD System of National Accounts (SNA) and employment data from TiVA. These allow computing countries' relative endowment of capital to labour, here calculated as the log of the average real net fixed assets per worker, as well as the capital intensity of industries for the year 2011. The capital intensity of an industry corresponds here to the share of net fixed assets per worker. In the baseline estimation, the average over all PIAAC countries is used and a rank index is constructed to rank industries according to their capital intensities. ${ }^{20}$ The relative endowment of countries in skilled to unskilled workers as well as the skill intensity of industries is computed using data about the country- and industry-level share of workers with different educational attainments from the World Input-Output Database (WIOD) ${ }^{21}$ for the year 2009 (the closest to the 2011, given that data for 2011 are not available). ${ }^{22}$ The relative endowment of countries in skilled to unskilled workers is computed as the log of the ratio of the number of workers having completed a secondary or tertiary degree divided by the number of workers having not completed a secondary degree. The skill intensity of an industry is computed as the share of workers having completed a secondary or tertiary degree, whereby the average over all PIAAC countries is used and a rank index is constructed to rank industries according to their skill intensities. ${ }^{23}$

Data on bilateral trade barriers have been gathered from the Centre d'Études Prospectives et d'Informations Internationales (CEPII) database. ${ }^{24}$ The following time invariant trade barrier variables are included in the estimates proposed: log of bilateral distances as well as dummy variables for common colonisers; common language; sharing a common border; having ever had a colonial link.

\section{Empirical strategy}

Building on the recent empirical literature on comparative advantage and specialisation of countries in international trade (Bombardini et al. 2012, Chor 2010, Davis and Weinstein 2001, Rajan and Zingales 1998), the following bilateral trade model at the industry level for the year 2011 is estimated:

$$
\begin{aligned}
& \ln (\text { exports })_{i, j, k} \\
& \theta_{j}+\delta_{k}+u_{i, j, k}
\end{aligned}=\alpha_{0}+\alpha_{1} \text { Endow }_{i} \times \text { Index }_{k}+\alpha_{2} \ln \left(\text { (1) } \text { final demand }_{j, k}+x_{i, k}{ }^{\prime} \beta+z_{i, j}{ }^{\prime} \gamma+\mu_{i}+\right.
$$

For exporting country $i$, importing country $j$ and industry $k$.

The dependent variable is the log of bilateral exports, estimated in gross or value added terms. As a third dependent variable, the authors use the valued added created in home country $i$ and industry $k$ embedded in final demand of foreign country $j .{ }^{25}$ The independent variable of interest is an interaction term between a country's specific endowment characteristic (Endow $\left.{ }_{i}\right)$ and an industry-specific characteristic (Index ${ }_{k}$ ). For the Ohnsorge and Trefler (2007) specification, an industry specific relative skill intensity measure is used, whereas for the Bombardini et al.'s specification an industry-level measure proxying the complementarity of production enters the specification. ${ }^{26}$ The independent variables of interest for the two different specifications are explained in more detail in the subsections below.

All specifications include the $\log$ of the final demand in industry $k$ of the importing country $j$ to account for the effects of demand forces on bilateral exports. Furthermore, the following variables $z$ from the CEPII database are included to control for bilateral trade barriers: the log of bilateral distance; dummy variables for common colonisers, common language, sharing a common border and having ever had a colonial link. Moreover, two different sets of dummy variables are included in the specifications. The set D1 includes dummy variables for exporting $\left(\mu_{\mathrm{i}}\right)$ and importing country $\left(\theta_{\mathrm{j}}\right)$ as well as for industries $\left(\delta_{\mathrm{k}}\right)$. 
The set of dummy variables D2 is richer than the first one, and includes industry dummy variables $\left(\delta_{\mathrm{k}}\right)$ as well as dummy variables that control for all omitted aggregated sector characteristics for each exporting and each importing country. To this end, the 34 industries are aggregated into the three macro sectors, namely resource extraction, manufacturing and utilities and services. Robust standard errors are clustered at the exporter-importer level.

Additionally, in terms of control variables, this study relies on the standard determinants $(x)$ of countries' specialisation in international trade (based on relative factor endowments) used in empirical studies on comparative advantage (Bombardini et al. 2012, Chor 2010, Nunn 2007, Levshenko 2007). The interaction term of the countries' relative endowment in capital to labour (in logs) with an index ranking industries according to their relative intensity in physical capital captures the effect of the relative endowment of capital to labour on the specialisation of countries in international trade. In addition, the interaction term of the countries' relative endowment in skilled to unskilled labour (in logs) with an index ranking industries according to their relative skill intensity (measured by educational attainment) controls for the effect of relative skill endowments on specialisation patterns, as done in existing studies (e.g. Bombardini et al. 2012). ${ }^{27}$

\section{Specification used to test the theoretical prediction of Ohnsorge and Trefler (2007)}

This work tests two of the channels identified in the theoretical model of Ohnsorge and Trefler (2007), namely the effect of $\rho$, i.e. the correlation of comparative and absolute advantage of workers, as well as the effect of the relative skill endowment on the specialisation of countries in international trade and in GVCs. ${ }^{28}$

To test the prediction of Ohnsorge and Treffler (2007) on the importance of skill bundles for countries' specialisation in international trade, this study interacts $\rho$, the country specific correlation of relative and absolute advantage of workers (in two types of cognitive skills), with the relative intensity of industries in the two specific task indicators that correspond to these two cognitive skills. For example, in the case of problem solving and literacy (as assessed cognitive skills) and the corresponding relative task intensity of industries in Self-Organisation vs. Management and Communication, the study interacts the country-specific correlation of comparative advantage (i.e. the log of the ratio of problem solving to literacy) and the absolute advantage (i.e. log of literacy) of workers with the measure that ranks industries according to their relative intensity in Self-Organisation vs. Management and Communication (larger rank numbers indicating higher intensity values).

According to Ohnsorge and Trefler (2007), one should expect a positive coefficient $\left(\alpha_{1}\right)$ for the interaction term between the country correlation measure and the relative industry intensity. A country characterised by a high positive correlation of comparative advantage (in problem solving to literacy) and absolute advantage should specialise in industries that are intensive in Self-Organisation tasks relative to Management and Communication tasks and export more in those industries. For example a country like the United Kingdom, which shows a strong negative correlation for problem solving and literacy (Figure 1), should be expected to have a comparative advantage in industries that are relatively less intensive in SelfOrganisation (and relatively more intensive in management and communication), like the Finance and Insurance Industries and other services sectors (see Table A5). Compared to a country with a higher correlation, like e.g. Japan, the United Kingdom is expected to export relatively more in products that are relatively less intensive in Self-Organisation (e.g. the services sectors, see Table A5).

To test the relative skill endowment channel predicted by Ohnsorge and Treffler (2007), this study interacts the country-specific relative endowment in two types of cognitive skills with the relative intensity of industries in the corresponding task-based skill indicators. For example, in the case of problem solving and literacy, the authors interact the country specific average of the (log of the) ratio of problem solving to 
literacy scores with the measure that ranks industries according to their relative intensity in SelfOrganisation vs. Management and Communication (larger rank numbers indicating higher intensity values).

According to the prediction of Ohnsorge and Trefler (2007), one should expect a positive coefficient $\left(\alpha_{1}\right)$ for the interaction term between a country's relative skill endowment measure and the relative industry intensity. If a country possesses a high relative endowment in problem solving relative to literacy, it should specialise in industries that are intensive in Self-Organisation tasks relative to Management and Communication tasks and export more in those industries. Comparing a country with a high relative endowment in problem solving to literacy, like Germany (Figure 2), with a country showing a low relative endowment, like Poland, one would expect that Germany would export relatively more in products that are relatively more intensive in Self-Organisation (and relatively less intensive in Management and Communication), like many manufacturing sectors (Table A5).

For the estimation, the authors include both interaction terms aimed at testing the two different predictions of Ohnsorge and Trefler (2007) in the same specification. This allows identifying the effect of one possible channel on how the joint skill distribution may affect specialisation patterns, while the other possible channel is held constant (an important assumption for the theoretical predictions). ${ }^{29}$ According to the predictions of the model, one would expect positive coefficients for both interaction terms.

To address possible concerns about the correspondence between the endowment measures (i.e. the assessed cognitive skills) and the industry skill intensity measures used, the authors also estimate specifications using the assessed cognitive skills (e.g. problem solving and literacy) to define the relative skill intensities of industries. This relative skill intensity measure is then interacted with the country endowment measures computed using the two cognitive skills (e.g. problem solving and literacy). In the literature on comparative advantage, it is common to use the same type of measures to compute countries' relative endowments and relative industry intensities. For example, the share of unskilled workers is used to define the relative skill endowment of countries as well as the relative skill intensity of industries (Bombardini et al. 2012). Results are robust to using the assessed cognitive skills to define industry skill intensities instead of using the task-based skill indicators, fact which is reassuring. ${ }^{30}$

\section{Specification used to test the theoretical prediction of Bombardini et al. (2012)}

To test the predictions of Bombardini et al. (2012), this study interacts the country wide residual skill distribution with the industry measure of skill complementarity in production, i.e. a measure ranking industries according to their intensity in Management and Communication tasks (larger rank numbers indicating higher intensity values). Three types of cognitive skills are used here, namely literacy, numeracy and problem solving, to compute the residual skill distribution. Thus, all specifications are estimated using each one of the cognitive skill for which data are available.

According to the predictions of Bombardini et al. (2012), one would expect a negative sign for the coefficient $\left(\alpha_{1}\right)$ for the interaction term of the residual skill distribution $\left(\right.$ Endow $\left._{\mathrm{i}}\right)$ and the industry measure for complementarity in production (Index $\mathrm{x}_{\mathrm{k}}$ ). A country with a lower dispersion in skills (as denoted by the negative coefficient) is likely to specialise and export products from industries that are more complementary in production. For example, a country like Japan with a low level of "residual skill dispersion" (Figure 3) should specialise in industries that are more complementary in production, e.g. the computer manufacturing industries and other manufacturing industries (Table A6). 


\section{Results}

\section{Results for the predictions of Ohnsorge and Trefler (2007)}

Table 2 presents the results for the test of two of the channels identified in the theoretical model of Ohnsorge and Trefler (2007), namely the effect of $\rho$, i.e. the correlation of comparative and absolute advantage of workers, as well as the effect of the relative skill endowment on the specialisation of countries in international trade and in GVCs.

Both interaction terms aimed at testing the two different predicted channels of Ohnsorge and Trefler (2007) are included in the same specification. A pair of rows in Table 2 corresponds to one specification. This includes both interaction terms, namely: the interaction of the country specific correlation of comparative and absolute advantage with the industry specific relative skill intensity measure; as well as the interaction of the country-specific relative skill endowment with the industry-specific relative skill intensity measure.

The upper panel A shows the results for the dependent variable gross exports, panel B for exports in value added terms and panel $\mathrm{C}$ for domestic value added embedded in foreign final demand. As mentioned, the specifications are estimated for all three possible combinations of assessed cognitive skills (namely, problem solving and literacy, problem solving and numeracy and numeracy and literacy) and their corresponding relative skill-intensity measures. The specification in column 1 includes the basic dummy variable set D1 (i.e. industry, exporter and importer dummy variables), column 2 includes additional dummy variables for aggregated sectors in the exporting and the importing country (D2). All specifications additionally include the final demand of the importing country at the industry level, bilateral trade costs as well as independent variables that control for other possible drivers of countries' specialisation in international markets, related to differences in the relative endowments of capital to labour and skilled to unskilled labour.

Table 2 only presents the estimated coefficients for the two independent variables of interest, which are: the interaction of the country-specific correlation of comparative and absolute advantage with the industry specific relative skill intensity measure (first of two rows); and the interaction of the countryspecific relative skill endowment with the industry-specific relative skill intensity measure (second of two rows). ${ }^{31}$ The results provide robust evidence in favour of the two predictions of Ohnsorge and Trefler (2007) for all three possible combinations of assessed skills.

Table 2 Coefficients for Ohnsorge and Trefler (2007)

\begin{tabular}{|c|c|c|c|c|}
\hline $\begin{array}{c}\text { Countries' } \\
\text { correlation of } \\
\text { comparative and } \\
\text { absolute skill } \\
\text { advantage of } \\
\text { workers }\end{array}$ & $\begin{array}{l}\text { Countries' average } \\
\text { relative endowment } \\
\text { of skills per worker }\end{array}$ & $\begin{array}{l}\text { Industry relative tasks } \\
\text { intensity (rank index) }\end{array}$ & & \\
\hline \multicolumn{5}{|c|}{ Panel A: Dependent Variable - Log of gross exports } \\
\hline ProbSolv and Lit & ProbSolv and Lit & $\begin{array}{l}\text { Self-Organisation / } \\
\text { Management }\end{array}$ & $\begin{array}{c}(1) \\
0.093^{\star \star \star} \\
0.237^{\star \star *}\end{array}$ & $\begin{array}{c}(2) \\
0.076^{\star \star \star} \\
0.219^{\star \star \star}\end{array}$ \\
\hline ProbSolv and Num & ProbSolv and Num & $\begin{array}{l}\text { Self-Organisation / } \\
\text { Marketing }\end{array}$ & $\begin{array}{l}0.109^{\star \star \star} \\
0.203^{\star \star *}\end{array}$ & $\begin{array}{l}0.075^{\star * *} \\
0.184^{\star \star *}\end{array}$ \\
\hline Num and Lit & Num and Lit & Marketing / Management & $\begin{array}{l}0.041^{\star * *} \\
0.294^{\star * *}\end{array}$ & $\begin{array}{c}0.010 \\
0.267^{\star \star \star}\end{array}$ \\
\hline
\end{tabular}




\begin{tabular}{|c|c|c|c|c|}
\hline \multicolumn{5}{|c|}{ Panel B: Dependent Variable - Log of value added exports } \\
\hline \multirow{3}{*}{ ProbSolv and Lit } & & \multirow{3}{*}{$\begin{array}{l}\text { Self-Organisation / } \\
\text { Management }\end{array}$} & (1) & (2) \\
\hline & & & $0.092^{\star \star \star}$ & $0.075^{\star * *}$ \\
\hline & ProbSolv and Lit & & $0.253^{\star \star \star}$ & $0.245^{\star \star *}$ \\
\hline \multirow[t]{2}{*}{ ProbSolv and Num } & & \multirow{2}{*}{$\begin{array}{c}\text { Self-Organisation / } \\
\text { Marketing }\end{array}$} & $0.106^{\star \star \star}$ & $0.07^{\star \star *}$ \\
\hline & ProbSolv and Num & & $0.176^{\star \star \star}$ & $0.127^{\star \star *}$ \\
\hline \multirow[t]{2}{*}{ Num and Lit } & & \multirow{2}{*}{ Marketing / Management } & $0.045^{\star \star \star}$ & $0.015^{\star}$ \\
\hline & Num and Lit & & $0.31^{\star \star \star}$ & $0.27^{\star \star \star}$ \\
\hline \multicolumn{5}{|c|}{ Panel C: Dependent Variable- Log of domestic value added embedded in foreign final demand } \\
\hline \multirow{3}{*}{ ProbSolv and Lit } & & & (1) & (2) \\
\hline & & Self-Organisation / & $0.056^{\star \star \star}$ & $0.045^{\star \star \star}$ \\
\hline & ProbSolv and Lit & Management & $0.286^{\star \star \star}$ & $0.293^{\star \star \star}$ \\
\hline \multirow[t]{2}{*}{ ProbSolv and Num } & & Self-Organisation / & $0.064^{\star \star *}$ & $0.038^{\star * *}$ \\
\hline & ProbSolv and Num & Marketing & $0.315^{\star \star \star}$ & $0.26^{\star \star \star}$ \\
\hline \multirow[t]{2}{*}{ Num and Lit } & & \multirow{2}{*}{ Marketing / Management } & -0.003 & $-0.018^{\star \star *}$ \\
\hline & Num and Lit & & $0.247^{\star \star \star}$ & $0.246^{\star \star \star}$ \\
\hline \multirow{3}{*}{\multicolumn{2}{|c|}{ Additional Control Variables }} & HO Control Variables & $\mathrm{Y}$ & $\mathrm{Y}$ \\
\hline & & Trade costs & Y & $\mathrm{Y}$ \\
\hline & & Additional dummy variables & D1 & D2 \\
\hline
\end{tabular}

Source: Authors' own compilation on data from PIAAC, TiVA and other sources.

Legend: Lit = Literacy; Num = Numeracy; ProbSolv = Problem Solving.

Note: Dependent variables are bilateral trade flows measured in gross terms (Panel A), in value added terms (Panel B) and the domestic value added embedded in foreign final demand (Panel C). The dataset includes 23 exporting countries, 61 partner countries and 34 TiVA industries for the year 2011. Each row-pair of the table corresponds to a single specification, whereby the interaction terms capturing the skill correlation channel and the relative skill endowment channel, respectively, enter together in one specification. Different row pairs use different definitions for the skill correlations and for relative skill endowments as well as industry intensity measures. Each column represents a different specification regarding the inclusion of certain sets of dummy variables. All specifications include the final demand at the importer-industry level as independent variable. Traditional Heckscher-Ohlin-(HO)Controls include the interaction of countries relative endowment of physical capital to workers (in logs) interacted with an index ranking industries according to their relative intensity in physical capital as well as the interaction of countries relative endowment in skilled to unskilled workers (in logs) interacted with an index ranking industries according to their relative skill intensity. Trade costs include bilateral trade cost variables from the CEPII database (log of bilateral distance as well as a dummy variable for common colonizer, common language, sharing a common border and having ever had a colonial link). The set of dummy variables used in D1 includes dummy variables for exporting and importing country as well as for industries. D2 includes additional dummy variables that control for all omitted aggregated sector characteristics for the exporting and importing country (34 industries are aggregated into the three sectors resource extraction, manufacturing and utilities as well as services). Robust SE are clustered at the exporter-importer level $\left({ }^{\star \star \star} p<0.01,{ }^{\star \star} p<0.05,{ }^{*} p<0.1\right)$.

When using problem solving and literacy or problem solving and numeracy to measure the skills correlation and the relative skill endowment of workers, the estimated coefficients for both interaction terms are significant and show the expected positive sign in all specifications. As predicted by Ohnsorge and Trefler (2007), a country with a high correlation between the comparative advantage of workers, measured as the ratio of problem solving to literacy, and the absolute advantage of workers, measured in terms of literacy, indeed specialises in industries that are relatively more intensive in Self-organisation than in Management and Communication (first row of each panel in Table 2). Thereby, specialisation refers to countries exporting more in gross and value added terms as well as in domestic value added embedded in foreign final demand. The same is true for the case of using problem solving and numeracy to measure workers skill bundles. 
The results are also in line with the second prediction of Ohnsorge and Trefler (2007) on the effect of the relative skill endowment on the specialisation of countries in international trade and in GVCs. A country with a high relative endowment in problem solving to literacy skills will specialise, i.e. will export more in gross and value added terms as well as in domestic valued added embedded in foreign final demand, in industries that are relatively more intensive in Self-organisation than in Management and Communication (second row of each panel in Table 2). The same is true for the case of problem solving and numeracy. In the case of using numeracy and literacy as skill bundle measures, the specification using gross or value added exports are also in line with both predictions of Ohnsorge and Trefler (2007); only when using the third dependent variable in Panel $\mathrm{C}$ the coefficient for the skills correlation channel becomes negative.

To illustrate the magnitude of the effects of the joint skill distribution on specialisation patterns, simple partial equilibrium comparative statics have been calculated for some country pairs as in Bombardini et al. (2012). The estimates for the correlation of comparative and absolute advantage of workers (using problem solving and literacy as cognitive skills, Table 2, Panel B and column 2), imply the following differences in exports in value added terms for two countries that differ with respect to the endowment of problem solving and literacy (Japan and United Kingdom) and two industries that differ in their relative skill intensity in Self-Organisation vs. Management and Communication, namely machinery and equipment and finance and insurance. The estimate for the interaction term of the correlation of comparative and absolute advantage and the relative skill intensity (0.075) implies that exports in value added in machinery and equipment relative to exports in finance and insurance (to any other foreign country) are 55\% higher in Japan than in the United Kingdom.

This effect is due to the skill bundle - sorting mechanism described by Ohnsorge and Trefler (2007). In the United Kingdom, which has a very low negative correlation of comparative and absolute advantage $(-0.48)$, workers with an absolute advantage (in problem solving and literacy) specialise in industries that are relatively more intensive in management and communication tasks (and less in problem solving tasks as proxied by the Self-Organisation indicator), e.g. the finance and insurance industry. ${ }^{32}$ Thus, the United Kingdom will have its best workers in those industries and is internationally very competitive in finance and insurance industries. In Japan, the correlation of comparative and absolute advantage (for problem solving and literacy) is close to zero (-0.07), and thus workers with an absolute advantage in both skills are dispersed across all industries and do not exclusively go to the finance and insurance industries. In relative terms, Japan will thus have relatively more exports in manufacturing and equipment compared to finance and insurance than the United Kingdom.

Regarding the second prediction of Ohnsorge and Trefler (2007) on the effects of the average relative skill endowment per worker on specialisation in international markets, the magnitude implied by the estimated coefficients is generally smaller than the magnitude of the effects of the correlation of comparative and absolute advantage of workers. For the example of problem solving and literacy and the countries Germany and the United States, the estimated coefficient for the interaction term of the country specific relative skill endowment with the industry specific relative skill intensity measure (0.245) implies that exports in value added in machinery and equipment relative to exports in finance and insurance (to any other foreign country) are $11 \%$ higher in Germany than in the United States.

This is due to the fact that the relative endowment of problem solving to literacy in Germany (0.024) is higher than the one of the United States (-0.002), i.e. the average ratio of problem solving to literacy per worker is higher in Germany. This means that Germany is endowed with relatively more workers with a comparative advantage in industries that are relatively more intensive in problem solving. Manufacturing and equipment industries are more intensive in problem solving tasks than in communication tasks (i.e. they are more intensive in Self-Organisation vs. Management and Communication) compared to finance and insurance industries. Because Germany has relatively more workers with a comparative advantage in 
manufacturing and equipment industries (relative to finance and insurance) compared to the USA, it is relatively cheaper to produce manufacturing and equipment products in Germany than in the USA and hence Germany will export relatively more manufacturing products than the USA.

\section{Average magnitudes of the effects of the joint skill distribution on specialisation patterns}

Table 3 shows the average magnitudes of the effects implied by the coefficient estimates in Table 2 (column 2). To this end, the relative changes in the dependent variable (i.e. value added exports in Panel B) for a standard deviation change in the independent variables of interest are calculated. If the correlation between the comparative advantage and the absolute advantage of workers (measured using e.g. problem solving and literacy) increases by one standard deviation, value added exports in an industry that has a one standard deviation higher relative intensity (in Self-organisation vs. Management and Communication) than another industry increase by $7.7 \%$ (relative to that of the other industry). For the relative skill endowment channel, the same exercise leads to an increase in value added exports by $4 \%$.

To compare the magnitude of these trade effects of the country-wide joint skill distribution to the magnitudes implied by traditional measures of relative factor endowments used in empirical analysis of comparative advantage, we apply the same approach using the estimated coefficients for the traditional Heckscher-Ohlin controls shown in Table A3. If a country increases its relative endowment of skilled to unskilled workers (measured by educational attainment) by one standard deviation, its value added exports in an industry that has a higher skill intensity by one standard deviation (than another industry) increase by $6.8 \%$ (relative to that of the other industry). For countries' relative endowment in capital to labour, the same exercise leads to an increase in value added exports by $4.1 \%$.

Thus, this study finds empirical evidence that the mix of skills at the worker level (skill bundle) indeed plays an important role for the production process as well as for countries' specialisation and integration into the world economy and into GVCs. The combined effect of the country endowment with skill bundles, as measured by the correlation of relative and absolute comparative advantage of workers and the average relative skill endowment per workers, is significantly larger in magnitude than the effect of the relative endowment of capital to labour. Furthermore, it is not only the countries' relative endowment with different types of workers possessing each a single type of skill (i.e. the typical Heckscher-OhlinEffect) that matters for production and specialisation in international trade, but rather the endowment with workers who possess more than one skill. This study finds that the combined trade effect of the country endowment in skill bundles is significantly larger in magnitude than the effect of the relative endowment of skilled to unskilled workers measured by educational attainment.

To compare the implied magnitudes of the results for all three possible measures of workers skill bundles, Table 3 shows the relative changes in the dependent variable value added exports for a standard deviation change in the independent variables of interest for all three combinations of assessed cognitive skills. Each column corresponds to a different specification using the specific combination of cognitive skills to measure the skill bundles of workers (equal to Panel B, column 2 of Table 2). The results for the combination of problem solving and numeracy (column 2) are very similar to the described results for the combination of problem solving and literacy (column 1). 
Table 3: Averages magnitudes implied by the coefficients of Panel B, column 2 in Table 2

\begin{tabular}{|c|c|c|c|}
\hline Workers Skill Bundle measured as: & $\begin{array}{c}\text { Problem Solving } \\
\text { and Literacy }\end{array}$ & $\begin{array}{c}\text { Problem Solving } \\
\text { and Numeracy }\end{array}$ & $\begin{array}{c}\text { Numeracy and } \\
\text { Literacy }\end{array}$ \\
\hline \multicolumn{2}{|c|}{ Independent Variables } & \multicolumn{2}{|c|}{ Dependent variable value added exports increases by: } \\
\hline $\begin{array}{c}\text { Countries' correlation of comparative and } \\
\text { absolute skill advantage of workers * Industry } \\
\text { Rank of Relative Task Intensity }\end{array}$ & $7.7 \%$ & $7.5 \%$ & $2.1 \%$ \\
\hline $\begin{array}{c}\text { Countries' Average Relative Endowment of Skills } \\
\text { per worker * }\end{array}$ & $4 \%$ & $3.2 \%$ & $7.3 \%$ \\
\hline $\begin{array}{c}\text { Industry Rank of Relative Task Intensity } \\
\text { Countries' Relative Endowment of Skilled to } \\
\text { Unskilled Workers *ndustry Rank of Skill } \\
\text { Intensity (educational attainment) }\end{array}$ & $6.8 \%$ & $5.1 \%$ & $9.7 \%$ \\
\hline $\begin{array}{c}\text { Countries' Relative Endowment of Capital to } \\
\text { Labour * Industry Rank of Capital Intensity }\end{array}$ & $4.1 \%$ & $3.6 \%$ & $4.9 \%$ \\
\hline
\end{tabular}

Source: Authors' own compilation on data from PIAAC, TiVA and other sources.

Note: This table shows the percentage change of the dependent variable "valued added exports" in an industry relative to another industry (which has a one standard deviation lower skill intensity) that are implied by a one standard deviation change in the country specific endowment. The three columns correspond to the three specifications in Panel B, column 2 of Table 2. In addition to Table 2, we also include the following independent variables: interaction of countries relative endowment of physical capital to workers (in logs) interacted with an index ranking industries according to their relative intensity in physical capital as well as the interaction of countries relative endowment in skilled to unskilled workers (in logs) interacted with an index ranking industries according to their relative skill intensity. Details on the empirical specifications are described in the note to Table 2.

However, when using numeracy and literacy to measure workers' skill bundles, the specialisation effect explained by the correlation of comparative and absolute skill advantages of workers is much lower than compared to using problem solving and literacy or problem solving and numeracy. The effect of the average relative skill endowment of workers on countries specialisation patterns becomes larger. Moreover, the specialisation effects explained by the relative endowment of skilled to unskilled workers (measured by educational attainment) increase strongly in the specification using numeracy and literacy to measure skill bundles of workers. This indicates that the combination of numeracy and literacy skills might not measure as important and distinct skill dimensions as the combinations involving problem solving skills. When using the combination of numeracy and literacy, the general measure of educational attainment explains a larger part of countries specialisation patterns than the joint skills bundle distribution.

This indicates that problem solving skills are a distinct set of skills compared to literacy and numeracy skills and that problem solving skills are important for the production and international specialisation of industries. Thus, to influence the industrial structure of their economies, countries might consider focusing on the relative endowment of their workers with problem solving skills compared to literacy and numeracy skills. Changing the relative endowment of workers with problem solving skill compared to literacy (or numeracy) skills has much stronger effects on international specialisation in GVCs than changing the relative endowment of workers with literacy compared to numeracy skills.

\section{Results for the predictions of Bombardini et al. (2012)}

Table 4 presents the results for the specifications testing the prediction of Bombardini et al. (2012). The upper panel A shows the results for the dependent variable gross exports, panel B for exports in value added terms and panel $\mathrm{C}$ for domestic value added embedded in foreign final demand. Results are presented for all three assessed cognitive skills that are used to measure the residual skill dispersion in countries. The specification in column 1 includes the basic dummy variable set D1 (i.e. industry, exporter and importer dummy variables), column 2 includes additional dummy variables for aggregated sectors in the exporting and the importing country (D2). All specifications additionally include the final demand of the importing country at the industry level, bilateral trade costs as well as independent variables that control for other possible drivers of countries' specialisation in international markets, related to differences in the relative endowments of capital to labour and skilled to unskilled labour. 
Table 4 only presents the estimated coefficients for the independent variable of interest, i.e. the interaction of the country-specific residual skill dispersion with the industry-specific measure of skill complementarity. ${ }^{33}$ For the preferred specification (column 2) and for the case of using problem solving to measure the residual skill dispersion of countries, the estimated coefficient is significant and shows the expected negative sign. As predicted by Bombardini et al. (2012), a country with a high residual skill dispersion indeed specialises, i.e. exports more in gross and value added terms, in industries that show a lower skill complementary (i.e. have a low value in the indicator Management and Communication).

Table 4 Coefficients for Bombardini et al. (2012)

\begin{tabular}{|c|c|c|c|}
\hline $\begin{array}{l}\text { Countries residual } \\
\text { skill dispersion }\end{array}$ & $\begin{array}{c}\text { Industry skill } \\
\text { complementarity (rank } \\
\text { index) }\end{array}$ & & \\
\hline \multicolumn{4}{|c|}{ Panel A: Dependent Variable - Log of gross exports } \\
\hline $\begin{array}{c}\text { Literacy } \\
\text { Numeracy } \\
\text { Problem Solving }\end{array}$ & $\begin{array}{l}\text { Management and } \\
\text { Communication }\end{array}$ & $\begin{array}{c}(1) \\
0.288^{\star \star \star} \\
0.598^{\star \star \star} \\
-0.531^{\star \star \star}\end{array}$ & $\begin{array}{c}(2) \\
-0.109 \\
0.399^{\star \star \star} \\
-0.474^{\star \star *}\end{array}$ \\
\hline \multicolumn{4}{|c|}{ Panel B: Dependent Variable - Log of value added exports } \\
\hline $\begin{array}{c}\text { Literacy } \\
\text { Numeracy } \\
\text { Problem Solving }\end{array}$ & $\begin{array}{l}\text { Management and } \\
\text { Communication }\end{array}$ & $\begin{array}{c}(1) \\
0.301^{\star \star \star} \\
0.572^{\star \star \star} \\
-0.509^{\star \star \star}\end{array}$ & $\begin{array}{c}(2) \\
-0.047 \\
0.408^{\star \star \star} \\
-0.413^{\star \star \star}\end{array}$ \\
\hline \multicolumn{4}{|c|}{ Panel C: Dependent Variable - Log of domestic value added embedded in foreign final demand } \\
\hline $\begin{array}{c}\text { Literacy } \\
\text { Numeracy } \\
\text { Problem Solving }\end{array}$ & $\begin{array}{l}\text { Management and } \\
\text { Communication }\end{array}$ & $\begin{array}{c}(1) \\
0.438^{\star \star \star} \\
0.515^{\star \star \star} \\
-0.302^{\star \star \star}\end{array}$ & $\begin{array}{c}(2) \\
0.162^{\star \star \star} \\
0.411^{\star \star \star} \\
-0.308^{\star \star \star}\end{array}$ \\
\hline $\begin{array}{l}\text { Additional Control } \\
\text { Variables }\end{array}$ & $\begin{array}{l}\text { HO Control Variables } \\
\text { Trade costs } \\
\text { Additional dummy } \\
\text { variables }\end{array}$ & $\begin{array}{l}Y \\
Y \\
D 1\end{array}$ & $\begin{array}{c} \\
Y \\
D 2\end{array}$ \\
\hline
\end{tabular}

Source: Authors' own compilation on data from PIAAC, TiVA and other sources

Note: Dependent variables are bilateral trade flows measured in gross terms (Panel A), in value added terms (Panel B) and the domestic value added embedded in foreign final demand (Panel C). The dataset includes 23 exporting countries, 61 partner countries and 34 TiVA industries for the year 2011. Each cell of the table corresponds to a single specification. Rows use different definitions for the residual skill dispersion. Each column represents a different specification regarding the inclusion of certain sets of dummy variables. All specifications include the final demand at the importer-industry level as independent variable. Traditional HeckscherOhlin-(HO)-Controls include the interaction of countries relative endowment of physical capital to workers (in logs) interacted with an index ranking industries according to their relative intensity in physical capital as well as the interaction of countries relative endowment in skilled to unskilled workers (in logs) interacted with an index ranking industries according to their relative skill intensity. Trade costs include bilateral trade cost variables from the CEPII database (log of bilateral distance as well as a dummy variable for common coloniser, common language, sharing a common border and having ever had a colonial link). The set of dummy variables used in D1 includes dummy variables for exporting and importing country as well as for industries. D2 includes additional dummy variables that control for all omitted aggregated sector characteristics for the exporting and importing country (34 industries are aggregated into the three sectors resource extraction, manufacturing and utilities as well as services). Robust SE are clustered at the exporter-importer level (*** $\left.p<0.01,{ }^{* *} p<0.05,{ }^{*} p<0.1\right)$.

However, the negative effects are not significant when using literacy to measure countries' residual skill dispersion. When using numeracy, the effects become even positive and significant. This may be due to the fact that numeracy is less well suited to proxy for the residual skill dispersion that influences the production of industries in the theoretical model of Bombardini et al. (2012). In their paper, the authors opt to only use literacy to measure the residual skill dispersion of countries, although numeracy was also 
available as a measure in the International Adult Literacy Survey (IALS) (see Ohnsorge and Trefler 2007, who compute basic descriptive correlations using numeracy and literacy from the IALS). ${ }^{34}$ This analysis shows that problem solving skills might be even better suited than literacy to proxy for the residual distribution of skills that are important for the production process.

To illustrate the magnitude of the effects that are implied by the coefficient estimates of Table 4 (column 2), simple partial equilibrium comparative statics as in Bombardini et al. (2012) have been calculated. The estimate for using problem solving to measure the country-specific residual skill dispersion, imply the following differences in exports in value added for two countries that differ with respect to the residual skill dispersion (e.g. Germany and Poland show a dispersion of 0.14 and 0.17, respectively) and two industries that differ in their skill complementarity in production (e.g. computer, electronic and optical products and food products which rank 22th and $4^{\text {th }}$ in the complementarity index, respectively). The estimate for the interaction term of the country-specific residual skill dispersion and industry-specific skill complementarity (-0.413) implies that exports in value added in computer, electronic and optical products relative to exports in food products (to any other foreign country) are $22 \%$ higher in Germany than in Poland.

This effect is due to the fact that firms in the computer, electronics and optical industries in Poland face a higher residual skill dispersion than in Germany, which leads to relatively higher production costs and lower output compared to food production. As the production of computer, electronics and optical products shows a relatively higher degree of skill complementarity, a more dispersed residual skill distribution of the work force is detrimental for the production process.

To illustrate the average magnitudes of the effects that are implied by the coefficient estimates of Table 4 (column 2), the authors compute the relative changes in the dependent variable (value added exports in Panel B) for a standard deviation change in the independent variables of interest using problem solving to measure the country-specific residual skill dispersion. If residual skill dispersion increases by one standard deviation, value added exports in an industry that has a skill complementarity in production higher by one standard deviation than another industry increase by $5.4 \%$ (relative to that other industry). This effect is comparable to the magnitudes implied by traditional measures of relative factor endowments, i.e. relative endowments of skilled to unskilled workers and relative endowment of capital to labour, which are $6.8 \%$ and $4.1 \%$, respectively.

\section{Conclusions}

Taken together, the results presented above highlight the existence of strong relations between the international fragmentation of production and the skill endowments of countries. In particular, this study finds strong empirical evidence that the mix of skills at the worker level, i.e. their skill bundle, plays an important role for countries' industrial specialisation and their integration into GVCs. The magnitude of the implied effects of the distribution of skills' bundles is larger than the trade effects predicted by the relative endowment of capital to labour, which shows that skills are key for economies to thrive in GVCs. It is not only countries' relative endowment of different types of workers possessing each a single type of skill (i.e. the typical Heckscher-Ohlin-Effect) that matters for production and specialisation in international trade, but rather the endowment of workers possessing more than one skill.

GVCs are creating new opportunities and challenges for skills development. For countries to better integrate into and benefit the most from their connection to international production networks, education policies should aim at equipping all citizens with a mix of literacy, numeracy and problem-solving skills, as well as with managing and communication, marketing and accounting and self-organisation skills. This in turn calls for the need to guarantee the quality of general education, throughout the lifetime of 
individuals, the removal of barriers to access education and life-long learning, and improvements in the recognition of skills.

Policies focusing only on selected specific skills rather than bundles of skills may reduce the ability of countries to appropriate the benefits of GVC participation. This may require, among others, adapting the curricula in tertiary education to combine the teaching of cognitive and soft skills, i.e. STEM or problem solving skills need to be complemented with communication and team working skills. Furthermore, lifelong learning and training should target the skill needs required by the evolutions of a country's production structure. Policies targeting the development of a given industry can be inefficient and reduce a country's comparative advantage if skills do not match the requirements of the industry. As a consequence, effort should be put in understanding and anticipating the skills required in production, and how to effectively deploy the existing human capital. This, in turn, requires strengthening the coordination between the private sector and the education system.

This study further highlights that education and skills policies, often thought to be only remotely linked to industrial and trade policies, strongly influence countries' industrial structure and specialisation in international trade, through shaping the within country distribution of skills. Enhanced coordination and alignment of industrial and trade policies with education and skills policies thus seems to be necessary to avoid counteracting policies and arising inefficiencies. As educational institutions and settings, as well as their effect on countries' skill endowments are generally more persistent than other institutions (Bombardini et al. 2012), the careful design of education and skills policies is key. They further need to be aligned with other policies affecting industry structure and performance and specialisation in international trade.

Furthermore, this study also finds evidence that problem solving skills are a somewhat distinct set of skills compared to the basic skills literacy and numeracy and that problem solving skills are especially important for the production and international specialisation of industries. Changing the relative endowment of workers with problem solving skills compared to literacy (or numeracy) skills may have a much stronger effect on international specialisation in GVCs than changing the relative endowment of workers with literacy compared to numeracy skills. It remains an important area of future policy-relevant research to explore which education and skills policies can shape the type of problem solving skills that seem to be crucial for industries to thrive in a global economy. 


\section{APPENDIX}

Table A1: Coefficients for Ohnsorge and Trefler (2007) (using continuous measures for industry characteristics)

\begin{tabular}{|c|c|c|c|c|}
\hline $\begin{array}{l}\text { Countries' correlation } \\
\text { of comparative and } \\
\text { absolute skill } \\
\text { advantage of workers }\end{array}$ & $\begin{array}{l}\text { Countries' average } \\
\text { relative endowment of } \\
\text { skills per worker }\end{array}$ & $\begin{array}{c}\text { Industry relative tasks } \\
\text { intensity (continuous } \\
\text { measure) }\end{array}$ & & \\
\hline \multicolumn{5}{|c|}{ Panel A: Dependent Variable - Log of gross exports } \\
\hline ProbSolv and Lit & ProbSolv and Lit & $\begin{array}{l}\text { Self-Organisation / } \\
\text { Management }\end{array}$ & $\begin{array}{c}(1) \\
3.82^{\star \star \star} \\
14.694^{\star \star}\end{array}$ & $\begin{array}{c}(2) \\
9.247^{\star \star \star} \\
28.317^{\star \star \star}\end{array}$ \\
\hline ProbSolv and Num & ProbSolv and Num & Self-Organisation / Marketing & $\begin{array}{l}12.069^{\star * *} \\
12.193^{\star *}\end{array}$ & $\begin{array}{l}8.142^{\star \star \star} \\
11.485^{\star \star}\end{array}$ \\
\hline Num and Lit & Num and Lit & Marketing / Management & $\begin{array}{c}2.1^{\star \star \star *} \\
20.293^{\star \star *}\end{array}$ & $\begin{array}{c}0.091 \\
19.31^{\star * \star}\end{array}$ \\
\hline \multicolumn{5}{|c|}{ Panel B: Dependent Variable - Log of value added exports } \\
\hline ProbSolv and Lit & ProbSolv and Lit & $\begin{array}{l}\text { Self-Organisation / } \\
\text { Management }\end{array}$ & $\begin{array}{c}(1) \\
3.848^{\star \star \star} \\
14.35^{\star \star}\end{array}$ & $\begin{array}{c}(2) \\
8.978^{\star \star \star} \\
28.126^{\star \star \star}\end{array}$ \\
\hline ProbSolv and Num & ProbSolv and Num & Self-Organisation / Marketing & $\begin{array}{c}11.914^{\star \star \star} \\
10.428^{\star}\end{array}$ & $\begin{array}{c}7.704^{\star \star \star} \\
5.835\end{array}$ \\
\hline Num and Lit & Num and Lit & Marketing / Management & $\begin{array}{l}2.353^{\star \star \star} \\
21.014^{\star \star \star}\end{array}$ & $\begin{array}{c}0.412 \\
19.387^{\star * *}\end{array}$ \\
\hline \multicolumn{5}{|c|}{ Panel C: Dependent Variable- Log of domestic value added embedded in foreign final demand } \\
\hline ProbSolv and Lit & ProbSolv and Lit & $\begin{array}{l}\text { Self-Organisation / } \\
\text { Management }\end{array}$ & $\begin{array}{c}(1) \\
1.83^{\star \star \star} \\
8.397^{\star \star}\end{array}$ & $\begin{array}{c}(2) \\
5.772^{\star \star \star} \\
24.26^{\star \star \star}\end{array}$ \\
\hline ProbSolv and Num & ProbSolv and Num & Self-Organisation / Marketing & $\begin{array}{c}6.584^{\star \star *} \\
26.038^{\star \star \star}\end{array}$ & $\begin{array}{c}3.908^{\star \star *} \\
22.145^{\star \star \star}\end{array}$ \\
\hline Num and Lit & Num and Lit & Marketing / Management & $\begin{array}{c}-0.058^{\star} \\
18.348^{\star \star \star}\end{array}$ & $\begin{array}{l}-1.447^{\star \star \star} \\
19.877^{\star \star *}\end{array}$ \\
\hline \multicolumn{2}{|c|}{ Additional Control Variables } & $\begin{array}{l}\text { HO Control Variables } \\
\text { Trade costs } \\
\text { Additional dummy variables }\end{array}$ & $\begin{array}{c}\mathrm{Y} \\
\mathrm{Y} \\
\mathrm{D} 1\end{array}$ & $\begin{array}{c}\mathrm{Y} \\
\mathrm{Y} \\
\mathrm{D} 2\end{array}$ \\
\hline
\end{tabular}

Source: Authors' own compilation on data from PIAAC, TiVA and other sources.

Legend: Lit = Literacy; Num = Numeracy; ProbSolv = Problem Solving

Note: Dependent variables are bilateral trade flows measured in gross terms (Panel A), in value added terms (Panel B) and the domestic value added embedded in foreign final demand (Panel C). The dataset includes 23 exporting countries, 61 partner countries and 34 TiVA industries for the year 2011. Each row-pair of the table corresponds to a single specification, whereby the interaction terms capturing the skill correlation channel and the relative skil endowment channel, respectively, enter together in one specification. Different row pairs use different definitions for the skill correlations and for relative skill endowments as well as for the continuous industry intensity measures. Each column represents a different specification regarding the inclusion of certain sets of dummy variables. All specifications include the final demand at the importer-industry level as independent variable. Traditional HeckscherOhlin-(HO)-Controls include the interaction of countries relative endowment of physical capital to workers (in logs) interacted with the industry intensity in physical capital as well as the interaction of countries relative endowment in skilled to unskilled workers (in logs) interacted with the industry skill intensity. Trade costs include bilateral trade cost variables from the CEPII database (log of bilateral distance as well as a dummy variable for common colonizer, common language, sharing a common border and having ever had a colonial link). The set of dummy variables used in D1 includes dummy variables for exporting and importing country as well as for industries. D2 includes additional dummy variables that control for all omitted aggregated sector characteristics for the exporting and importing country (34 industries are aggregated into the three sectors resource extraction, manufacturing and utilities as well as services). Robust SE are clustered at the exporter-importer level $\left({ }^{\star \star \star} p<0.01,{ }^{\star \star} p<0.05,{ }^{*} p<0.1\right)$. 
Table 2. Table A2: Coefficients for Bombardini et al. (2012) (using continuous measures for industry characteristics)

\begin{tabular}{|c|c|c|c|}
\hline $\begin{array}{l}\text { Countries' residual } \\
\text { skill dispersion }\end{array}$ & $\begin{array}{c}\text { Industry skill } \\
\text { complementarity } \\
\text { (continuous } \\
\text { measure) }\end{array}$ & & \\
\hline \multicolumn{4}{|c|}{ Panel A: Dependent Variable - Log of gross exports } \\
\hline $\begin{array}{c}\text { Literacy } \\
\text { Numeracy } \\
\text { Problem Solving }\end{array}$ & $\begin{array}{l}\text { Management and } \\
\text { Communication }\end{array}$ & $\begin{array}{c}(1) \\
35.072 * * \\
100.453 * * * \\
-98.744 * * *\end{array}$ & $\begin{array}{c}(2) \\
3.534 \\
85.650 * * * \\
-79.015 * * *\end{array}$ \\
\hline \multicolumn{4}{|c|}{ Panel B: Dependent Variable - Log of value added exports } \\
\hline $\begin{array}{c}\text { Literacy } \\
\text { Numeracy } \\
\text { Problem Solving }\end{array}$ & $\begin{array}{l}\text { Management and } \\
\text { Communication }\end{array}$ & $\begin{array}{c}(1) \\
36.795 * * \\
95.413 * * * \\
-97.42 * * *\end{array}$ & $\begin{array}{c}(2) \\
13.412 \\
86.553^{* * *} \\
-71.097 * * *\end{array}$ \\
\hline \multicolumn{4}{|c|}{ Panel C: Dependent Variable - Log of domestic value added embedded in foreign final demand } \\
\hline $\begin{array}{c}\text { Literacy } \\
\text { Numeracy } \\
\text { Problem Solving }\end{array}$ & $\begin{array}{l}\text { Management and } \\
\text { Communication }\end{array}$ & $\begin{array}{c}(1) \\
62.994 * * * \\
87.610^{* * *} \\
-38.356 * * *\end{array}$ & $\begin{array}{c}(2) \\
41.299 * * * \\
84.471^{* * *} \\
-28.206 * * *\end{array}$ \\
\hline $\begin{array}{c}\text { Additional Control } \\
\text { Variables }\end{array}$ & $\begin{array}{c}\text { HO Control } \\
\text { Variables } \\
\text { Trade costs } \\
\text { Additional dummy } \\
\text { variables }\end{array}$ & $\begin{array}{l}\mathrm{Y} \\
\mathrm{Y} \\
\mathrm{D} 1\end{array}$ & $\begin{array}{c}\mathrm{Y} \\
\mathrm{Y} \\
\mathrm{D} 2\end{array}$ \\
\hline
\end{tabular}

Source: Authors' own compilation on data from PIAAC, TiVA and other sources.

Legend: Lit = Literacy; Num = Numeracy; ProbSolv = Problem Solving.

Note: Dependent variables are bilateral trade flows measured in gross terms (Panel A), in value added terms (Panel B) and the domestic value added embedded in foreign final demand (Panel C). The dataset includes 23 exporting countries, 61 partner countries and 34 TiVA industries for the year 2011. Each cell of the table corresponds to a single specification. Rows use different definitions for the residual skill dispersion. Each column represents a different specification regarding the inclusion of certain sets of dummy variables. All specifications include the final demand at the importer-industry level as independent variable. Traditional HeckscherOhlin-(HO)-Controls include the interaction of countries relative endowment of physical capital to workers (in logs) interacted with industry capital intensity as well as countries relative endowment in skilled to unskilled workers (in logs) interacted with industry skill intensity. Trade costs include bilateral trade cost variables from the CEPII database (log of bilateral distance as well as a dummy variable for common colonizer, common language, sharing a common border and having ever had a colonial link). The set of dummy variables used in D1 includes dummy variables for exporting and importing country as well as for industries. D2 includes additional dummy variables that control for all omitted aggregated sector characteristics for the exporting and importing country (34 industries are aggregated into the three sectors resource extraction, manufacturing and utilities as well as services). Robust SE are clustered at the exporter-importer level $\left({ }^{* *} p<0.01,{ }^{* *} p<0.05,{ }^{*} p<0.1\right)$. 
Table A3: Table 2 with Control Variables

\begin{tabular}{|c|c|c|c|}
\hline VARIABLES & $\begin{array}{l}\text { (1) } \\
\text { Log of gross } \\
\text { exports }\end{array}$ & $\begin{array}{c}(2) \\
\text { Log of value } \\
\text { added exports }\end{array}$ & $\begin{array}{c}(3) \\
\text { Log of the dom. } \\
\text { value added in } \\
\text { foreign final } \\
\text { demand }\end{array}$ \\
\hline \multirow[t]{2}{*}{$\begin{array}{l}\text { Countries' correlation of comparative and absolute skill } \\
\text { advantage of workers (problem solving and } \\
\text { literacy)*Industry Rank of Relative Task Intensity in Self- } \\
\text { Organization vs. Management and Communication }\end{array}$} & $0.076^{\star \star *}$ & $0.075^{\star \star \star}$ & $0.045^{\star \star *}$ \\
\hline & $(0.012)$ & $(0.012)$ & $(0.006)$ \\
\hline \multirow[t]{2}{*}{$\begin{array}{c}\text { Countries' Average Relative Endowment of Problem Solving } \\
\text { to Literacy* Industry Rank of Relative Task Intensity in Self- } \\
\text { Organization vs. Management and Communication }\end{array}$} & $0.219 * \star \star$ & $0.245^{\star \star \star}$ & $0.293^{\star \star \star}$ \\
\hline & $(0.075)$ & $(0.077)$ & $(0.045)$ \\
\hline \multirow[t]{2}{*}{$\begin{array}{c}\text { Countries' Relative Endowment of Skilled to Unskilled } \\
\text { Workers * Industry Rank of Skill Intensity (educational } \\
\text { attainment) }\end{array}$} & $0.009 * \star \star$ & $0.008^{* * *}$ & 0.000 \\
\hline & $(0.002)$ & $(0.002)$ & $(0.001)$ \\
\hline $\begin{array}{l}\text { Countries' Relative Endowment of Capital to Labour * } \\
\text { Industry Rank of Capital Intensity }\end{array}$ & $\begin{array}{l}0.008^{\star \star \star} \\
(0.002)\end{array}$ & $\begin{array}{l}0.008^{* \star *} \\
(0.002)\end{array}$ & $\begin{array}{l}0.006^{\star * \star} \\
(0.001)\end{array}$ \\
\hline Log of Final Demand of the Importer & $\begin{array}{l}0.179 * \star \star \\
(0.014)\end{array}$ & $\begin{array}{l}0.180 * * \star \\
(0.014)\end{array}$ & $\begin{array}{l}0.082^{\star \star \star} \\
(0.007)\end{array}$ \\
\hline Common Border & $\begin{array}{c}0.073 \\
(0.176)\end{array}$ & $\begin{array}{c}0.091 \\
(0.174)\end{array}$ & $\begin{array}{c}0.118 \\
(0.122)\end{array}$ \\
\hline Common Language between ethnicities in the country & $\begin{array}{l}0.330^{\star \star *} \\
(0.096)\end{array}$ & $\begin{array}{l}0.333^{\star * *} \\
(0.095)\end{array}$ & $\begin{array}{l}0.240 * * * \\
(0.062)\end{array}$ \\
\hline Ever had colonial links & $\begin{array}{l}0.655^{\star \star \star} \\
(0.136)\end{array}$ & $\begin{array}{l}0.647^{* * *} \\
(0.133)\end{array}$ & $\begin{array}{l}0.406^{\star \star \star} \\
(0.098)\end{array}$ \\
\hline Common Colonizer & $\begin{array}{l}2.133^{\star} \\
(1.101)\end{array}$ & $\begin{array}{l}2.097^{\star} \\
(1.082)\end{array}$ & $\begin{array}{l}1.711^{*} \\
(0.968)\end{array}$ \\
\hline Log of Distance & $\begin{array}{l}-1.353^{\star * \star} \\
(0.043)\end{array}$ & $\begin{array}{l}-1.342^{\star \star \star} \\
(0.042)\end{array}$ & $\begin{array}{c}-0.942^{\star \star \star} \\
(0.029)\end{array}$ \\
\hline Constant & $\begin{array}{c}12.786^{\star \star \star} \\
(0.674)\end{array}$ & $\begin{array}{c}12.593^{\star \star \star} \\
(0.670)\end{array}$ & $\begin{array}{c}11.556^{\star \star \star} \\
(0.387)\end{array}$ \\
\hline Observations & 33,413 & 33,201 & 34,986 \\
\hline R-squared & 0.756 & 0.753 & 0.889 \\
\hline Adjusted R-squared & 0.755 & 0.751 & 0.889 \\
\hline
\end{tabular}

Source: Authors' own compilation on data from PIAAC, TiVA and other sources.

Note: Dependent variables are bilateral trade flows measured in gross terms (1), in value added terms (2) and the domestic value added embedded in foreign final demand (3). The dataset includes 23 exporting countries, 61 partner countries and 34 TiVA industries for the year 2011. All specifications include the final demand at the importer-industry level as independent variable. Traditional Heckscher-Ohlin-(HO)-Controls include the interaction of countries' relative endowment of physical capital to workers (in logs) interacted with an index ranking industries according to their relative intensity in physical capital as well as the interaction of countries' relative endowment in skilled to unskilled workers (in logs) interacted with an index ranking industries according to their relative skill intensity. Trade costs include bilateral trade cost variables from the CEPII database (log of bilateral distance as well as a dummy variable for common colonizer, common language, sharing a common border and having ever had a colonial link). All specifications include dummy variables for exporting and importing country, for industries as well as additional dummy variables that control for all omitted aggregated sector characteristics for the exporting and importing country (34 industries are aggregated into the three sectors resource extraction, manufacturing and utilities as well as services). Robust SE are clustered at the exporter-importer level $\left({ }^{* *} p<0.01,{ }^{* *} p<0.05,{ }^{*} p<0.1\right)$. 
Table A4: Table 4 with Control Variables

\begin{tabular}{|c|c|c|c|}
\hline VARIABLES & $\begin{array}{l}\text { (1) } \\
\text { Log of gross } \\
\text { exports }\end{array}$ & $\begin{array}{c}\text { (2) } \\
\text { Log of value } \\
\text { added exports }\end{array}$ & $\begin{array}{l}\text { (3) } \\
\text { Log of the dom. } \\
\text { value added in } \\
\text { foreign final } \\
\text { demand }\end{array}$ \\
\hline \multirow{2}{*}{$\begin{array}{l}\text { Country Residual Skill dispersion (Problem Solving) } \\
\text { *Industry Ranking in Communication Intensity }\end{array}$} & $-0.474^{\star \star \star}$ & $-0.413^{\star \star \star}$ & $-0.308^{\star \star \star}$ \\
\hline & $(0.077)$ & $(0.080)$ & $(0.051)$ \\
\hline \multirow{2}{*}{$\begin{array}{l}\text { Countries' Relative Endowment of Skilled to Unskilled } \\
\text { Workers * Industry Rank of Skill Intensity (educational } \\
\text { attainment) }\end{array}$} & $0.010 * \star \star$ & $0.009 * \star \star$ & 0.001 \\
\hline & $(0.002)$ & $(0.002)$ & $(0.001)$ \\
\hline \multirow{2}{*}{$\begin{array}{c}\text { Countries' Relative Endowment of Capital to Labour * } \\
\text { Industry Rank of Capital Intensity }\end{array}$} & $0.007^{\star \star \star}$ & $0.007^{\star \star \star}$ & $0.005^{\star \star \star}$ \\
\hline & $(0.001)$ & $(0.002)$ & $(0.001)$ \\
\hline \multirow[t]{2}{*}{ Log of Final Demand of the Importer } & $0.179 * \star *$ & $0.180^{\star * *}$ & $0.082^{\star \star \star}$ \\
\hline & $(0.014)$ & $(0.014)$ & $(0.007)$ \\
\hline \multirow[t]{2}{*}{ Common Border } & 0.072 & 0.090 & 0.118 \\
\hline & $(0.176)$ & $(0.174)$ & $(0.122)$ \\
\hline \multirow[t]{2}{*}{ Common Language between ethnicities in the country } & $0.330^{\star \star \star}$ & $0.333^{\star \star *}$ & $0.240 * \star \star$ \\
\hline & $(0.096)$ & $(0.095)$ & $(0.062)$ \\
\hline \multirow[t]{2}{*}{ Ever had colonial links } & $0.655^{\star \star \star}$ & $0.647^{\star \star *}$ & $0.406^{\star \star \star}$ \\
\hline & $(0.136)$ & $(0.133)$ & $(0.098)$ \\
\hline \multirow[t]{2}{*}{ Common Colonizer } & $2.134^{*}$ & $2.098^{*}$ & $1.711^{*}$ \\
\hline & $(1.102)$ & $(1.083)$ & $(0.968)$ \\
\hline \multirow[t]{2}{*}{ Log of Distance } & $-1.353^{\star \star \star}$ & $-1.342^{* \star *}$ & $-0.942^{\star \star \star}$ \\
\hline & $(0.043)$ & $(0.042)$ & $(0.029)$ \\
\hline \multirow[t]{2}{*}{ Constant } & $11.977^{\star \star *}$ & $11.771^{\star \star \star}$ & $11.154^{\star \star \star}$ \\
\hline & $(0.664)$ & $(0.663)$ & $(0.385)$ \\
\hline Observations & 33,413 & 33,201 & 34,986 \\
\hline R-squared & 0.756 & 0.753 & 0.889 \\
\hline Adjusted R-squared & 0.754 & 0.751 & 0.888 \\
\hline
\end{tabular}

Source: Authors' own compilation on data from PIAAC, TiVA and other sources.

Note: Dependent variables are bilateral trade flows measured in gross terms (1), in value added terms (2) and the domestic value added embedded in foreign final demand (3). The dataset includes 23 exporting countries, 61 partner countries and 34 TiVA industries for the year 2011. All specifications include the final demand at the importer-industry level as independent variable. Traditional Heckscher-Ohlin-(HO)-Controls include the interaction of countries relative endowment of physical capital to workers (in logs) interacted with an index ranking industries according to their relative intensity in physical capital as well as the interaction of countries relative endowment in skilled to unskilled workers (in logs) interacted with an index ranking industries according to their relative skill intensity. Trade costs include bilateral trade cost variables from the CEPII database (log of bilateral distance as well as a dummy variable for common colonizer, common language, sharing a common border and having ever had a colonial link). All specifications include dummy variables for exporting and importing country, for industries as well as additional dummy variables that control for all omitted aggregated sector characteristics for the exporting and importing country (34 industries are aggregated into the three sectors resource extraction, manufacturing and utilities as well as services). Robust SE are clustered at the exporter-importer level $\left({ }^{\star * *} p<0.01,{ }^{* \star} p<0.05,{ }^{*} p<0.1\right)$. 


\section{Descriptive Statistics}

Table A5: Statistics for relative task intensities of industries (average across countries)

\begin{tabular}{|c|c|c|c|c|c|c|c|}
\hline \multirow[b]{2}{*}{ TiVA 34} & \multirow[b]{2}{*}{ Description } & \multicolumn{2}{|c|}{$\begin{array}{l}\text { Self-Organisation to } \\
\text { Management }\end{array}$} & \multicolumn{2}{|c|}{$\begin{array}{l}\text { Self-Organisation to } \\
\text { Marketing }\end{array}$} & \multicolumn{2}{|c|}{$\begin{array}{l}\text { Marketing to } \\
\text { Management }\end{array}$} \\
\hline & & $\begin{array}{l}\text { Industry } \\
\text { Rank }\end{array}$ & $\begin{array}{l}\text { Ratio of } \\
\text { task int- } \\
\text { ensities }\end{array}$ & $\begin{array}{l}\text { Industry } \\
\text { Rank }\end{array}$ & $\begin{array}{l}\text { Ratio of } \\
\text { task int- } \\
\text { ensities }\end{array}$ & $\begin{array}{l}\text { Industry } \\
\text { Rank }\end{array}$ & $\begin{array}{l}\text { Ratio of } \\
\text { task int- } \\
\text { ensities }\end{array}$ \\
\hline 1 & Agriculture, hunting, forestry and fishing & 33 & 1.42 & 23 & 1.07 & 34 & 1.33 \\
\hline 2 & Mining and quarrying & 5 & 0.92 & 28 & 1.10 & 3 & 0.84 \\
\hline 3 & Food products, beverages and tobacco & 14 & 1.01 & 8 & 0.94 & 26 & 1.07 \\
\hline 4 & $\begin{array}{l}\text { Textiles, textile products, leather and } \\
\text { footwear }\end{array}$ & 21 & 1.05 & 9 & 0.95 & 27 & 1.10 \\
\hline 5 & Wood and products of wood and cork & 15 & 1.02 & 12 & 0.98 & 22 & 1.04 \\
\hline 6 & $\begin{array}{l}\text { Pulp, paper, paper products, printing and } \\
\text { publishing }\end{array}$ & 27 & 1.06 & 19 & 1.03 & 20 & 1.03 \\
\hline 7 & $\begin{array}{l}\text { Coke, refined petroleum products and } \\
\text { nuclear fuel }\end{array}$ & 6 & 0.93 & 10 & 0.96 & 13 & 0.97 \\
\hline 8 & Chemicals and chemical products & 23 & 1.05 & 26 & 1.09 & 12 & 0.96 \\
\hline 9 & Rubber and plastics products & 8 & 0.94 & 17 & 1.02 & 6 & 0.92 \\
\hline 10 & Other non-metallic mineral products & 29 & 1.07 & 24 & 1.08 & 15 & 0.99 \\
\hline 11 & Basic metals & 12 & 0.98 & 21 & 1.06 & 7 & 0.92 \\
\hline 12 & $\begin{array}{l}\text { Fabricated metal products except } \\
\text { machinery and equipment }\end{array}$ & 31 & 1.14 & 29 & 1.11 & 21 & 1.03 \\
\hline 13 & Machinery and equipment n.e.c & 25 & 1.06 & 25 & 1.09 & 14 & 0.97 \\
\hline 14 & Computer, electronic and optical products & 22 & 1.05 & 27 & 1.10 & 11 & 0.96 \\
\hline 15 & Electrical machinery and apparatus n.e.c & 17 & 1.03 & 14 & 1.00 & 19 & 1.02 \\
\hline 16 & Motor vehicles, trailers and semi-trailers & 20 & 1.04 & 30 & 1.12 & 8 & 0.93 \\
\hline 17 & Other transport equipment & 3 & 0.90 & 22 & 1.07 & 4 & 0.84 \\
\hline 18 & Manufacturing n.e.c; recycling & 24 & 1.05 & 13 & 1.00 & 25 & 1.06 \\
\hline 19 & Electricity, gas and water supply & 11 & 0.98 & 11 & 0.98 & 16 & 1.00 \\
\hline 20 & Construction & 26 & 1.06 & 15 & 1.01 & 24 & 1.05 \\
\hline 21 & Wholesale and retail trade; repairs & 13 & 1.01 & 3 & 0.83 & 32 & 1.21 \\
\hline 22 & Hotels and restaurants & 10 & 0.95 & 1 & 0.81 & 31 & 1.18 \\
\hline 23 & Transport and storage & 16 & 1.03 & 5 & 0.90 & 28 & 1.13 \\
\hline 24 & Post and telecommunications & 9 & 0.95 & 6 & 0.93 & 18 & 1.02 \\
\hline 25 & Finance and insurance & 7 & 0.93 & 2 & 0.82 & 29 & 1.14 \\
\hline 26 & Real estate activities & 32 & 1.18 & 7 & 0.94 & 33 & 1.26 \\
\hline 27 & Renting of machinery and equipment & 19 & 1.04 & 4 & 0.90 & 30 & 1.16 \\
\hline 28 & Computer and related activities & 28 & 1.06 & 31 & 1.14 & 10 & 0.94 \\
\hline 29 & $\begin{array}{l}\text { Research and development and Other } \\
\text { Business Activities }\end{array}$ & 30 & 1.07 & 18 & 1.02 & 23 & 1.05 \\
\hline 30 & $\begin{array}{l}\text { Public admin. and defence; compulsory } \\
\text { social security }\end{array}$ & 2 & 0.89 & 20 & 1.05 & 5 & 0.85 \\
\hline 31 & Education & 1 & 0.77 & 32 & 1.15 & 1 & 0.67 \\
\hline 32 & Health and social work & 4 & 0.90 & 33 & 1.16 & 2 & 0.77 \\
\hline 33 & $\begin{array}{l}\text { Other community, social and personal } \\
\text { services }\end{array}$ & 18 & 1.03 & 16 & 1.01 & 17 & 1.02 \\
\hline 34 & Private households with employed persons & 34 & 1.46 & 34 & 1.57 & 9 & 0.93 \\
\hline
\end{tabular}

Source: Authors' own compilation on data from PIAAC, TiVA and other sources. 
Table A6: Industry intensities in Management and Communication (average across countries)

\begin{tabular}{|c|c|c|c|}
\hline TiVA 34 & Description & $\begin{array}{c}\text { Industry } \\
\text { Rank }\end{array}$ & $\begin{array}{l}\text { Intensity } \\
\text { measure }\end{array}$ \\
\hline 1 & Agriculture, hunting, forestry and fishing & 1 & 0.365627 \\
\hline 2 & Mining and quarrying & 29 & 0.528843 \\
\hline 3 & Food products, beverages and tobacco & 4 & 0.419643 \\
\hline 4 & Textiles, textile products, leather and footwear & 5 & 0.420268 \\
\hline 5 & Wood and products of wood and cork & 3 & 0.40981 \\
\hline 6 & Pulp, paper, paper products, printing and publishing & 15 & 0.478549 \\
\hline 7 & Coke, refined petroleum products and nuclear fuel & 17 & 0.480204 \\
\hline 8 & Chemicals and chemical products & 25 & 0.502821 \\
\hline 9 & Rubber and plastics products & 14 & 0.47558 \\
\hline 10 & Other non-metallic mineral products & 10 & 0.443555 \\
\hline 11 & Basic metals & 18 & 0.483896 \\
\hline 12 & Fabricated metal products except machinery and equipment & 7 & 0.434721 \\
\hline 13 & Machinery and equipment n.e.c & 16 & 0.479522 \\
\hline 14 & Computer, electronic and optical products & 22 & 0.497746 \\
\hline 15 & Electrical machinery and apparatus n.e.c & 8 & 0.441361 \\
\hline 16 & Motor vehicles, trailers and semi-trailers & 9 & 0.441953 \\
\hline 17 & Other transport equipment & 21 & 0.496236 \\
\hline 18 & Manufacturing n.e.c; recycling & 11 & 0.466953 \\
\hline 19 & Electricity, gas and water supply & 23 & 0.498165 \\
\hline 20 & Construction & 13 & 0.470376 \\
\hline 21 & Wholesale and retail trade; repairs & 26 & 0.506352 \\
\hline 22 & Hotels and restaurants & 12 & 0.470184 \\
\hline 23 & Transport and storage & 6 & 0.427963 \\
\hline 24 & Post and telecommunications & 20 & 0.492299 \\
\hline 25 & Finance and insurance & 33 & 0.567949 \\
\hline 26 & Real estate activities & 24 & 0.500178 \\
\hline 27 & Renting of machinery and equipment & 28 & 0.528624 \\
\hline 28 & Computer and related activities & 32 & 0.554434 \\
\hline 29 & Research and development and Other Business Activities & 19 & 0.48685 \\
\hline 30 & Public admin. and defence; compulsory social security & 31 & 0.540697 \\
\hline 31 & Education & 34 & 0.640529 \\
\hline 32 & Health and social work & 30 & 0.532619 \\
\hline 33 & Other community, social and personal services & 27 & 0.516043 \\
\hline 34 & Private households with employed persons & 2 & 0.372425 \\
\hline
\end{tabular}

Source: Authors' own compilation on data from PIAAC, TiVA and other sources. 
Table A7: Rank correlations of relative industry intensities in Self-organisation vs. Management across countries

\begin{tabular}{|c|c|c|c|c|c|c|c|c|c|c|c|c|c|c|c|c|c|c|c|c|c|c|c|}
\hline & AUS & AUT & BEL & CAN & CZE & DEU & \begin{tabular}{|l|} 
DNK \\
\end{tabular} & ESP & EST & FIN & FRA* & GBR & $\mathrm{IRL}$ & ITA* & \begin{tabular}{|l|}
$J P N$ \\
\end{tabular} & KOR & NLD & NOR & $\mathrm{POL}$ & RUS & SVK & SWE & \begin{tabular}{|l|} 
USA \\
\end{tabular} \\
\hline AUT & 0.47 & & & & & & & & & & & & & & & & & & & & & & \\
\hline $\mathrm{BEL}$ & 0.63 & \begin{tabular}{|l|l|}
0.44 \\
\end{tabular} & & & & & & & & & & & & & & & & & & & & & \\
\hline CAN & 0.58 & 0.35 & 0.48 & & & & & & & & & & & & & & & & & & & & \\
\hline CZE & \begin{tabular}{|l|l|} 
\\
\end{tabular} & \begin{tabular}{|l}
0.37 \\
\end{tabular} & \begin{tabular}{|l}
0.22 \\
\end{tabular} & \begin{tabular}{|l|l|}
0.02 \\
\end{tabular} & & & & & & & & & & & & & & & & & & & \\
\hline DEU & 0.36 & 0.54 & 0.46 & \begin{tabular}{|l}
0.48 \\
\end{tabular} & 0.24 & 1 & & & & & & & & & & & & & & & & & \\
\hline DNK & 0.25 & 0.24 & 0.37 & 0.53 & 0.20 & 0.49 & - & & & & & & & & & & & & & & & & \\
\hline ESP* & 0.58 & \begin{tabular}{|l}
0.39 \\
\end{tabular} & \begin{tabular}{|l}
0.45 \\
\end{tabular} & \begin{tabular}{|l}
0.31 \\
\end{tabular} & \begin{tabular}{|l}
0.18 \\
\end{tabular} & 0.03 & \begin{tabular}{|l|}
0.24 \\
\end{tabular} & & & & & & & & & & & & & & & & \\
\hline EST & 0.46 & \begin{tabular}{|l}
0.39 \\
\end{tabular} & \begin{tabular}{|l}
0.34 \\
\end{tabular} & \begin{tabular}{|l}
0.56 \\
\end{tabular} & \begin{tabular}{|l}
0.33 \\
\end{tabular} & \begin{tabular}{|l}
0.49 \\
\end{tabular} & \begin{tabular}{|l|}
0.60 \\
\end{tabular} & \begin{tabular}{|l|}
0.21 \\
\end{tabular} & & & & & & & & & & & & & & & \\
\hline FIN & 0.56 & \begin{tabular}{|l|l|}
0.43 \\
\end{tabular} & \begin{tabular}{|l|l|}
0.41 \\
\end{tabular} & 0.40 & 0.21 & 0.24 & 0.46 & \begin{tabular}{|l|l|}
0.67 \\
\end{tabular} & \begin{tabular}{|l|l|} 
\\
\end{tabular} & & & & & & & & & & & & & & \\
\hline $\mathrm{FRA}^{*}$ & 0.22 & 0.33 & 0.26 & 0.62 & \begin{tabular}{|l|l|}
0.14 \\
\end{tabular} & 0.32 & \begin{tabular}{|l|l|} 
\\
\end{tabular} & 0.32 & 0.58 & 0.39 & - & & & & & & & & & & & & \\
\hline GBR & 0.38 & 0.49 & 0.19 & 0.39 & 0.12 & 0.58 & 0.54 & 0.21 & 0.42 & \begin{tabular}{|l|l|}
0.45 \\
\end{tabular} & 0.36 & & & & & & & & & & & & \\
\hline $\mathrm{IRL}$ & 0.67 & \begin{tabular}{|l}
0.46 \\
\end{tabular} & 0.36 & \begin{tabular}{|l}
0.55 \\
\end{tabular} & \begin{tabular}{|l|l}
0.21 \\
\end{tabular} & \begin{tabular}{|l|l|}
0.42 \\
\end{tabular} & \begin{tabular}{|l|}
0.31 \\
\end{tabular} & \begin{tabular}{|l|l|}
0.41 \\
\end{tabular} & \begin{tabular}{|l|}
0.58 \\
\end{tabular} & \begin{tabular}{|l|}
0.52 \\
\end{tabular} & \begin{tabular}{|l|}
0.21 \\
\end{tabular} & 0.45 & & & & & & & & & & & \\
\hline ITA* & 0.37 & \begin{tabular}{|l|l}
0.53 \\
\end{tabular} & \begin{tabular}{|l}
0.37 \\
\end{tabular} & \begin{tabular}{|l|l}
0.61 \\
\end{tabular} & 0.26 & \begin{tabular}{|l|l}
0.43 \\
\end{tabular} & \begin{tabular}{|l|}
0.49 \\
\end{tabular} & \begin{tabular}{|l|}
0.46 \\
\end{tabular} & \begin{tabular}{|l|l|}
0.64 \\
\end{tabular} & 0.43 & \begin{tabular}{|l|l|}
0.54 \\
\end{tabular} & 0.51 & \begin{tabular}{|l|l|}
0.44 \\
\end{tabular} & & & & & & & & & & \\
\hline JPN & 0.35 & \begin{tabular}{|l|l|}
0.11 \\
\end{tabular} & 0.35 & 0.51 & 0.26 & 0.41 & 0.58 & 0.23 & 0.59 & 0.37 & \begin{tabular}{|l|l|}
0.34 \\
\end{tabular} & 0.65 & \begin{tabular}{|l|}
0.37 \\
\end{tabular} & 0.56 & & & & & & & & & \\
\hline KOR & 0.11 & \begin{tabular}{|l}
0.36 \\
\end{tabular} & \begin{tabular}{|l|l|}
0.02 \\
\end{tabular} & \begin{tabular}{|l}
0.25 \\
\end{tabular} & \begin{tabular}{|l}
0.27 \\
\end{tabular} & \begin{tabular}{|l}
0.37 \\
\end{tabular} & 0.36 & \begin{tabular}{|l|l|}
0.15 \\
\end{tabular} & \begin{tabular}{|l|l|}
0.42 \\
\end{tabular} & \begin{tabular}{|l|l|} 
\\
\end{tabular} & \begin{tabular}{|l|l|}
0.14 \\
\end{tabular} & \begin{tabular}{|l|}
0.56 \\
\end{tabular} & \begin{tabular}{|l|}
0.35 \\
\end{tabular} & \begin{tabular}{|l|}
0.52 \\
\end{tabular} & 0.54 & & & & & & & & \\
\hline NLD & 0.83 & \begin{tabular}{|l}
0.49 \\
\end{tabular} & \begin{tabular}{|l}
0.73 \\
\end{tabular} & \begin{tabular}{|l|l}
0.64 \\
\end{tabular} & \begin{tabular}{|l}
0.18 \\
\end{tabular} & \begin{tabular}{|l|l|}
0.64 \\
\end{tabular} & 0.38 & \begin{tabular}{|l|l|}
0.42 \\
\end{tabular} & \begin{tabular}{|l|l|} 
\\
\end{tabular} & \begin{tabular}{|l|l|}
0.45 \\
\end{tabular} & \begin{tabular}{|l|}
0.33 \\
\end{tabular} & 0.44 & \begin{tabular}{|l|}
0.53 \\
\end{tabular} & \begin{tabular}{|l|}
0.53 \\
\end{tabular} & \begin{tabular}{|l|l|}
0.41 \\
\end{tabular} & 0.23 & & & & & & & \\
\hline NOR & 0.55 & 0.61 & 0.49 & 0.55 & 0.35 & 0.71 & 0.53 & 0.20 & 0.50 & 0.50 & 0.44 & 0.63 & \begin{tabular}{|l|l|} 
\\
\end{tabular} & 0.55 & 0.49 & 0.36 & 0.69 & & & & & & \\
\hline $\mathrm{POL}$ & \begin{tabular}{|l|l|} 
\\
\end{tabular} & \begin{tabular}{|l}
0.51 \\
\end{tabular} & \begin{tabular}{|l|l|}
0.44 \\
\end{tabular} & \begin{tabular}{|l|l|}
0.34 \\
\end{tabular} & \begin{tabular}{|l|l}
0.43 \\
\end{tabular} & \begin{tabular}{|l|}
0.34 \\
\end{tabular} & \begin{tabular}{|l|}
0.34 \\
\end{tabular} & \begin{tabular}{|l|l|}
0.41 \\
\end{tabular} & \begin{tabular}{|l|l|}
0.44 \\
\end{tabular} & \begin{tabular}{|l|l|}
0.48 \\
\end{tabular} & \begin{tabular}{|l|}
0.48 \\
\end{tabular} & 0.35 & \begin{tabular}{|l|}
0.27 \\
\end{tabular} & \begin{tabular}{|l|}
0.36 \\
\end{tabular} & \begin{tabular}{|l|}
0.30 \\
\end{tabular} & 0.34 & \begin{tabular}{|l|}
0.52 \\
\end{tabular} & \begin{tabular}{|l|l|}
0.42 \\
\end{tabular} & & & & & \\
\hline RUS & 0.43 & \begin{tabular}{|l|l}
0.34 \\
\end{tabular} & \begin{tabular}{|l}
0.03 \\
\end{tabular} & \begin{tabular}{|l|l|}
0.22 \\
\end{tabular} & \begin{tabular}{|l}
0.39 \\
\end{tabular} & \begin{tabular}{|l}
0.31 \\
\end{tabular} & \begin{tabular}{|l|l|}
0.14 \\
\end{tabular} & \begin{tabular}{|l}
0.23 \\
\end{tabular} & 0.29 & \begin{tabular}{|l|}
0.39 \\
\end{tabular} & \begin{tabular}{|l|}
0.12 \\
\end{tabular} & 0.42 & \begin{tabular}{|l|l|}
0.42 \\
\end{tabular} & \begin{tabular}{|l|}
0.06 \\
\end{tabular} & 0.24 & 0.29 & \begin{tabular}{|l|l|} 
\\
\end{tabular} & \begin{tabular}{|l|}
0.27 \\
\end{tabular} & \begin{tabular}{|l|}
0.22 \\
\end{tabular} & & & & \\
\hline SVK & 0.52 & 0.43 & 0.35 & 0.39 & 0.53 & 0.21 & \begin{tabular}{|l|l|} 
\\
\end{tabular} & \begin{tabular}{|l|l|}
0.40 \\
\end{tabular} & 0.34 & 0.34 & \begin{tabular}{|l|l|}
0.14 \\
\end{tabular} & 0.18 & \begin{tabular}{|l|l|}
0.42 \\
\end{tabular} & 0.47 & 0.29 & \begin{tabular}{|l|l|}
0.46 \\
\end{tabular} & 0.52 & 0.29 & \begin{tabular}{|l|}
0.58 \\
\end{tabular} & \begin{tabular}{|l|}
0.19 \\
\end{tabular} & & & \\
\hline SWE & 0.36 & 0.45 & 0.46 & 0.52 & 0.25 & 0.64 & 0.52 & 0.36 & $0.67 \mid$ & 0.47 & 0.46 & 0.37 & 0.57 & 0.51 & 0.44 & 0.26 & 0.43 & 0.39 & 0.39 & 0.46 & 0.32 & & \\
\hline USA & 0.25 & 0.59 & 0.29 & 0.38 & \begin{tabular}{|l|}
0.34 \\
\end{tabular} & 0.53 & 0.61 & \begin{tabular}{|l|l|}
0.12 \\
\end{tabular} & \begin{tabular}{|l|l|} 
\\
\end{tabular} & 0.34 & 0.53 & 0.45 & \begin{tabular}{|l|l|}
0.27 \\
\end{tabular} & 0.46 & 0.21 & 0.30 & 0.41 & 0.64 & 0.50 & \begin{tabular}{|l|l|}
0.11 \\
\end{tabular} & 0.20 & \begin{tabular}{|l|}
0.33 \\
\end{tabular} & \\
\hline WOR & 0.51 & 0.54 & 0.42 & 0.56 & 0.29 & \begin{tabular}{|l|l|}
0.58 \\
\end{tabular} & \begin{tabular}{|l}
0.76 \\
\end{tabular} & 0.38 & 0.74 & 0.55 & \begin{tabular}{|l|l|} 
\\
\end{tabular} & \begin{tabular}{|l|l|}
0.76 \\
\end{tabular} & \begin{tabular}{|l|l|}
0.49 \\
\end{tabular} & \begin{tabular}{|l|l|}
0.61 \\
\end{tabular} & 0.68 & 0.45 & \begin{tabular}{|l|l|}
0.59 \\
\end{tabular} & 0.68 & 0.64 & \begin{tabular}{|l|}
0.32 \\
\end{tabular} & 0.36 & 0.54 & \begin{tabular}{|l|l|}
0.76 \\
\end{tabular} \\
\hline
\end{tabular}

Source: Authors' own compilation on data from PIAAC, TiVA and other sources.

Note: WOR is the industry intensity averaged across countries (as used in the empirical specification to rank industries).

Table A8: Rank correlations of relative industry intensities in Marketing vs. Management across countries

\begin{tabular}{|c|c|c|c|c|c|c|c|c|c|c|c|c|c|c|c|c|c|c|c|c|c|c|c|}
\hline & $\mathrm{A} \cup \mathrm{S}$ & AUT & $\mathrm{BEL}$ & CAN & CZE & DEU & DNK & ESP & EST & FIN & FRA* & GBR & $\mathrm{IRL}$ & ITA* & JPN & KOR & NLD & NOR & $\mathrm{POL}$ & $R \cup S$ & SVK & SWE & \begin{tabular}{|l|} 
USA \\
\end{tabular} \\
\hline AUT & 0.80 & & & & & & & & & & & & & & & & & & & & & & \\
\hline BEL & 0.70 & 0.60 & & & & & & & & & & & & & & & & & & & & & \\
\hline CAN & 0.63 & \begin{tabular}{|l}
0.49 \\
\end{tabular} & 0.46 & & & & & & & & & & & & & & & & & & & & \\
\hline CZE & 0.73 & 0.59 & 0.58 & 0.78 & & & & & & & & & & & & & & & & & & & \\
\hline DEU & 0.73 & \begin{tabular}{|l}
0.72 \\
\end{tabular} & 0.68 & 0.65 & 0.66 & |- & & & & & & & & & & & & & & & & & \\
\hline DNK & \begin{tabular}{|l}
0.52 \\
\end{tabular} & 0.55 & 0.48 & 0.60 & 0.44 & \begin{tabular}{|l}
0.56 \\
\end{tabular} & & & & & & & & & & & & & & & & & \\
\hline ESP* & 0.69 & 0.69 & 0.53 & 0.65 & 0.61 & 0.69 & 0.72 & & & & & & & & & & & & & & & & \\
\hline EST & 0.81 & 0.74 & 0.62 & 0.75 & 0.82 & 0.79 & 0.67 & 0.79 & & & & & & & & & & & & & & & \\
\hline FIN & 0.67 & 0.66 & 0.67 & 0.67 & 0.59 & 0.61 & 0.57 & \begin{tabular}{|l|l|}
0.72 \\
\end{tabular} & 0.69 & & & & & & & & & & & & & & \\
\hline $\mathrm{FRA}^{*}$ & 0.64 & 0.53 & 0.52 & \begin{tabular}{|l} 
\\
\end{tabular} & 0.61 & 0.68 & 0.76 & \begin{tabular}{|l|l|}
0.71 \\
\end{tabular} & 0.66 & 0.63 & & & & & & & & & & & & & \\
\hline GBR & 0.54 & 0.56 & 0.46 & 0.54 & 0.39 & 0.55 & 0.54 & \begin{tabular}{|l|}
0.58 \\
\end{tabular} & \begin{tabular}{|l|}
0.61 \\
\end{tabular} & \begin{tabular}{|l|}
0.78 \\
\end{tabular} & \begin{tabular}{|l|}
0.53 \\
\end{tabular} & & & & & & & & & & & & \\
\hline IRL & 0.40 & 0.30 & 0.20 & 0.56 & 0.36 & \begin{tabular}{|l|l|}
0.24 \\
\end{tabular} & 0.60 & \begin{tabular}{|l|}
0.51 \\
\end{tabular} & 0.45 & 0.48 & 0.51 & 0.58 & & & & & & & & & & & \\
\hline ITA* & 0.73 & \begin{tabular}{|l}
0.76 \\
\end{tabular} & 0.57 & 0.59 & \begin{tabular}{|l|l}
0.61 \\
\end{tabular} & \begin{tabular}{|l}
0.75 \\
\end{tabular} & 0.58 & \begin{tabular}{|l}
0.66 \\
\end{tabular} & \begin{tabular}{|l|l|} 
\\
\end{tabular} & \begin{tabular}{|l|l|}
0.54 \\
\end{tabular} & \begin{tabular}{|l|}
0.72 \\
\end{tabular} & 0.40 & \begin{tabular}{|l|l|}
0.25 \\
\end{tabular} & & & & & & & & & & \\
\hline JPN & 0.55 & 0.39 & \begin{tabular}{|l}
0.50 \\
\end{tabular} & \begin{tabular}{|l}
0.77 \\
\end{tabular} & 0.65 & \begin{tabular}{|l|l|}
0.71 \\
\end{tabular} & 0.57 & \begin{tabular}{|l|l|}
0.45 \\
\end{tabular} & \begin{tabular}{|l|}
0.61 \\
\end{tabular} & \begin{tabular}{|l|l|}
0.57 \\
\end{tabular} & \begin{tabular}{|l|}
0.72 \\
\end{tabular} & 0.57 & \begin{tabular}{|l|l|}
0.41 \\
\end{tabular} & \begin{tabular}{|l}
0.56 \\
\end{tabular} & & & & & & & & & \\
\hline KOR & 0.54 & 0.59 & 0.41 & \begin{tabular}{|l|l|} 
\\
\end{tabular} & 0.62 & 0.60 & 0.48 & \begin{tabular}{|l|l} 
\\
\end{tabular} & \begin{tabular}{|l|}
0.69 \\
\end{tabular} & \begin{tabular}{|l|l|}
0.64 \\
\end{tabular} & \begin{tabular}{|l|}
0.51 \\
\end{tabular} & 0.63 & \begin{tabular}{|l|l|}
0.46 \\
\end{tabular} & \begin{tabular}{|l|l|}
0.44 \\
\end{tabular} & 0.60 & & & & & & & & \\
\hline NLD & 0.72 & \begin{tabular}{|l}
0.59 \\
\end{tabular} & 0.61 & 0.65 & 0.62 & \begin{tabular}{|l|}
0.71 \\
\end{tabular} & \begin{tabular}{|l} 
\\
\end{tabular} & \begin{tabular}{|l|l|}
0.70 \\
\end{tabular} & 0.74 & \begin{tabular}{|l|l|}
0.72 \\
\end{tabular} & \begin{tabular}{|l|}
0.64 \\
\end{tabular} & 0.66 & \begin{tabular}{|l|l|}
0.43 \\
\end{tabular} & 0.75 & 0.56 & 0.40 & & & & & & & \\
\hline NOR & 0.63 & \begin{tabular}{|l}
0.48 \\
\end{tabular} & 0.54 & 0.70 & 0.63 & \begin{tabular}{|l|l|}
0.69 \\
\end{tabular} & 0.37 & \begin{tabular}{|l|l|} 
\\
\end{tabular} & 0.57 & \begin{tabular}{|l|l|}
0.57 \\
\end{tabular} & \begin{tabular}{|l|}
0.72 \\
\end{tabular} & 0.56 & \begin{tabular}{|l|l}
0.27 \\
\end{tabular} & \begin{tabular}{|l}
0.70 \\
\end{tabular} & \begin{tabular}{|l}
0.65 \\
\end{tabular} & 0.53 & 0.66 & & & & & & \\
\hline $\mathrm{POL}$ & \begin{tabular}{|l|l|}
0.67 \\
\end{tabular} & 0.61 & 0.70 & 0.61 & 0.72 & \begin{tabular}{|l}
0.68 \\
\end{tabular} & 0.50 & \begin{tabular}{|l|l|} 
\\
\end{tabular} & \begin{tabular}{|l|}
0.75 \\
\end{tabular} & \begin{tabular}{|l|l|}
0.76 \\
\end{tabular} & \begin{tabular}{|l|}
0.51 \\
\end{tabular} & 0.60 & \begin{tabular}{|l|l|}
0.41 \\
\end{tabular} & 0.51 & 0.55 & \begin{tabular}{|l}
0.67 \\
\end{tabular} & \begin{tabular}{|l}
0.62 \\
\end{tabular} & \begin{tabular}{|l}
0.59 \\
\end{tabular} & & & & & \\
\hline RUS & 0.62 & 0.48 & 0.37 & 0.46 & 0.40 & 0.36 & 0.21 & 0.50 & 0.46 & 0.53 & \begin{tabular}{|l|l|} 
\\
\end{tabular} & 0.62 & 0.52 & 0.27 & 0.25 & 0.53 & \begin{tabular}{|l|l}
0.47 \\
\end{tabular} & \begin{tabular}{|l|l}
0.50 \\
\end{tabular} & \begin{tabular}{|l|l}
0.43 \\
\end{tabular} & & & & \\
\hline SVK & 0.66 & \begin{tabular}{|l}
0.59 \\
\end{tabular} & 0.73 & 0.53 & 0.69 & \begin{tabular}{|l}
0.76 \\
\end{tabular} & 0.45 & \begin{tabular}{|l|}
0.60 \\
\end{tabular} & \begin{tabular}{|l|}
0.71 \\
\end{tabular} & \begin{tabular}{|l|l|}
0.65 \\
\end{tabular} & \begin{tabular}{|l|}
0.51 \\
\end{tabular} & 0.52 & \begin{tabular}{|l|l|}
0.34 \\
\end{tabular} & 0.71 & \begin{tabular}{|l|l|}
0.54 \\
\end{tabular} & \begin{tabular}{|l}
0.58 \\
\end{tabular} & 0.72 & \begin{tabular}{|l}
0.70 \\
\end{tabular} & \begin{tabular}{|l}
0.71 \\
\end{tabular} & 0.39 & & & \\
\hline SWE & 0.71 & 0.69 & 0.75 & 0.66 & 0.70 & 0.76 & 0.56 & \begin{tabular}{|l|l|}
0.73 \\
\end{tabular} & 0.77 & 0.68 & 0.65 & 0.60 & \begin{tabular}{|l|l|}
0.44 \\
\end{tabular} & 0.67 & \begin{tabular}{|l}
0.62 \\
\end{tabular} & 0.52 & \begin{tabular}{|l|l}
0.73 \\
\end{tabular} & 0.60 & 0.64 & 0.50 & 0.70 & & \\
\hline \begin{tabular}{|l|} 
USA \\
\end{tabular} & 0.75 & \begin{tabular}{|l}
0.67 \\
\end{tabular} & 0.63 & 0.76 & 0.77 & 0.70 & 0.64 & 0.66 & \begin{tabular}{|l|} 
\\
\end{tabular} & 0.75 & \begin{tabular}{|l|l|}
0.70 \\
\end{tabular} & 0.58 & \begin{tabular}{|l|l}
0.47 \\
\end{tabular} & 0.70 & \begin{tabular}{|l|l|} 
\\
\end{tabular} & 0.60 & 0.71 & \begin{tabular}{|l|l|}
0.74 \\
\end{tabular} & \begin{tabular}{|l|l}
0.83 \\
\end{tabular} & \begin{tabular}{|l|l|}
3 & 0.44 \\
\end{tabular} & \begin{tabular}{|l|l|}
0.73 \\
\end{tabular} & 0.70 & 1 \\
\hline WOR & 0.83 & 0.71 & 0.64 & 0.84 & 0.84 & \begin{tabular}{|l}
0.78 \\
\end{tabular} & 0.65 & \begin{tabular}{|l|l|}
0.78 \\
\end{tabular} & 0.90 & \begin{tabular}{|l|l|} 
\\
\end{tabular} & 0.77 & 0.67 & 0.51 & 0.75 & 0.71 & 0.72 & 0.81 & \begin{tabular}{|l}
0.77 \\
\end{tabular} & 0.80 & 0.56 & 0.80 & 0.77 & \begin{tabular}{|l|l|}
0.92 \\
\end{tabular} \\
\hline
\end{tabular}

Source: Authors' own compilation on data from PIAAC, TiVA and other sources.

Note: WOR is the industry intensity averaged across countries (as used in the empirical specification to rank industries). 
Table A9: Rank correlations of relative industry intensities in Self-Organisation vs. Marketing across countries

\begin{tabular}{|c|c|c|c|c|c|c|c|c|c|c|c|c|c|c|c|c|c|c|c|c|c|c|c|}
\hline & AUS & AUT & BEL & CAN & CZE & DEU & DNK & ESP & EST & FIN & FRA* & बGR & IRL & ITA* & JPN & KOR & NLD & NOR & POL & RUS & SVK & SWE & USA \\
\hline AUT & 0.74 & - & & & & & & & & & & & & & & & & & & & & & \\
\hline BEL & 0.44 & 0.62 & - & & & & & & & & & & & & & & & & & & & & \\
\hline CAN & 0.66 & 0.50 & 0.50 & - & & & & & & & & & & & & & & & & & & & \\
\hline CZE & \begin{tabular}{|l|}
0.60 \\
\end{tabular} & \begin{tabular}{|l|}
0.79 \\
\end{tabular} & 0.41 & \begin{tabular}{|l|}
0.31 \\
\end{tabular} & - & & & & & & & & & & & & & & & & & & \\
\hline DEU & 0.34 & 0.63 & 0.54 & 0.24 & 0.62 & - & & & & & & & & & & & & & & & & & \\
\hline DNK & 0.60 & 0.64 & 0.70 & \begin{tabular}{|l|}
0.46 \\
\end{tabular} & 0.51 & 0.37 & - & & & & & & & & & & & & & & & & \\
\hline ESP* & 0.72 & 0.81 & 0.35 & 0.37 & 0.75 & 0.42 & 0.51 & - & & & & & & & & & & & & & & & \\
\hline EST & 0.60 & 0.55 & 0.45 & \begin{tabular}{|l|}
0.46 \\
\end{tabular} & 0.49 & 0.53 & 0.47 & 0.46 & - & & & & & & & & & & & & & & \\
\hline FIN & 0.45 & 0.55 & 0.65 & 0.58 & 0.32 & 0.38 & 0.55 & 0.50 & 0.43 & - & & & & & & & & & & & & & \\
\hline FRA* & 0.40 & 0.47 & 0.46 & 0.45 & 0.50 & 0.56 & 0.37 & 0.53 & 0.37 & \begin{tabular}{|l|}
0.47 \\
\end{tabular} & - & & & & & & & & & & & & \\
\hline \begin{tabular}{|l|} 
GBR \\
\end{tabular} & 0.33 & 0.45 & 0.60 & 0.44 & 0.18 & 0.38 & 0.55 & 0.16 & 0.40 & 0.49 & 0.22 & - & & & & & & & & & & & \\
\hline IRL & \begin{tabular}{|l|}
0.70 \\
\end{tabular} & \begin{tabular}{|l|}
0.59 \\
\end{tabular} & 0.39 & \begin{tabular}{|l|}
0.71 \\
\end{tabular} & \begin{tabular}{|l|}
0.44 \\
\end{tabular} & \begin{tabular}{|l|l|} 
\\
\end{tabular} & \begin{tabular}{|l|}
0.63 \\
\end{tabular} & 0.53 & 0.41 & \begin{tabular}{|l|}
0.43 \\
\end{tabular} & \begin{tabular}{|l|}
0.23 \\
\end{tabular} & 0.54 & - & & & & & & & & & & \\
\hline ITA* & 0.60 & 0.57 & 0.28 & 0.43 & 0.46 & 0.35 & 0.55 & 0.62 & 0.51 & 0.25 & 0.30 & 0.12 & 0.52 & - & & & & & & & & & \\
\hline JPN & 0.62 & 0.61 & 0.44 & \begin{tabular}{|l|l|}
0.18 \\
\end{tabular} & \begin{tabular}{|l|}
0.66 \\
\end{tabular} & 0.51 & 0.46 & 0.65 & 0.65 & 0.35 & 0.31 & 0.33 & 0.35 & 0.42 & - & & & & & & & & \\
\hline KOR & 0.46 & 0.55 & 0.59 & 0.46 & 0.44 & 0.59 & 0.59 & 0.28 & 0.68 & 0.32 & 0.34 & 0.67 & 0.39 & 0.43 & 0.63 & $3-$ & & & & & & & \\
\hline \begin{tabular}{|l|} 
NLD \\
\end{tabular} & \begin{tabular}{|l|}
0.57 \\
\end{tabular} & \begin{tabular}{|l|}
0.71 \\
\end{tabular} & 0.60 & \begin{tabular}{|l|}
0.59 \\
\end{tabular} & \begin{tabular}{|l|}
0.48 \\
\end{tabular} & \begin{tabular}{|l|}
0.38 \\
\end{tabular} & \begin{tabular}{|l|}
0.47 \\
\end{tabular} & 0.65 & 0.35 & \begin{tabular}{|l|}
0.66 \\
\end{tabular} & \begin{tabular}{|l|}
0.57 \\
\end{tabular} & 0.44 & \begin{tabular}{|l|}
0.57 \\
\end{tabular} & 0.26 & \begin{tabular}{|l|}
0.29 \\
\end{tabular} & 0.22 & - & & & & & & \\
\hline \begin{tabular}{|l|} 
NOR \\
\end{tabular} & 0.37 & 0.52 & 0.30 & 0.31 & 0.49 & 0.49 & 0.49 & 0.51 & 0.16 & 0.30 & 0.45 & 0.12 & 0.47 & 0.60 & 0.24 & 0.18 & 0.41 & - & & & & & \\
\hline $\mathrm{POL}$ & \begin{tabular}{|l|}
0.40 \\
\end{tabular} & \begin{tabular}{|l|}
0.51 \\
\end{tabular} & 0.56 & \begin{tabular}{|l|}
0.46 \\
\end{tabular} & \begin{tabular}{|l|}
0.46 \\
\end{tabular} & 0.53 & 0.40 & 0.42 & 0.48 & \begin{tabular}{|l|}
0.44 \\
\end{tabular} & \begin{tabular}{|l|}
0.57 \\
\end{tabular} & 0.42 & \begin{tabular}{|l|l|}
0.47 \\
\end{tabular} & 0.45 & 0.40 & 0.53 & 0.51 & 0.36 & - & & & & \\
\hline RUS & 0.29 & 0.40 & 0.34 & 0.36 & 0.32 & 0.55 & 0.31 & 0.26 & 0.59 & 0.42 & 0.37 & 0.71 & 0.30 & 0.20 & 0.48 & 0.69 & 0.33 & 0.06 & 0.51 & - & & & \\
\hline SVK & \begin{tabular}{|l|}
0.52 \\
\end{tabular} & 0.55 & 0.38 & \begin{tabular}{|l|}
0.35 \\
\end{tabular} & \begin{tabular}{|l|l|}
0.54 \\
\end{tabular} & 0.60 & 0.30 & 0.48 & 0.54 & \begin{tabular}{|l|}
0.28 \\
\end{tabular} & \begin{tabular}{|l|} 
\\
\end{tabular} & 0.23 & \begin{tabular}{|l|}
0.31 \\
\end{tabular} & 0.41 & \begin{tabular}{|l|}
0.61 \\
\end{tabular} & 0.51 & 0.47 & 0.44 & \begin{tabular}{|l|}
0.69 \\
\end{tabular} & \begin{tabular}{|l|}
0.47 \\
\end{tabular} & - & & \\
\hline SWE & 0.47 & 0.74 & 0.69 & \begin{tabular}{|l|}
0.27 \\
\end{tabular} & 0.54 & 0.76 & 0.53 & 0.52 & 0.50 & 0.50 & 0.40 & 0.45 & 0.23 & 0.38 & 0.48 & 0.53 & 0.56 & 0.45 & 0.55 & 0.45 & 0.57 & - & \\
\hline USA & \begin{tabular}{|l|}
0.54 \\
\end{tabular} & \begin{tabular}{|l|}
0.59 \\
\end{tabular} & 0.73 & \begin{tabular}{|l|}
0.45 \\
\end{tabular} & \begin{tabular}{|l|}
0.60 \\
\end{tabular} & 0.40 & \begin{tabular}{|l|}
0.65 \\
\end{tabular} & 0.48 & 0.43 & \begin{tabular}{|l|}
0.56 \\
\end{tabular} & \begin{tabular}{|l|}
0.35 \\
\end{tabular} & 0.38 & 0.53 & 0.50 & \begin{tabular}{|l|}
0.49 \\
\end{tabular} & 0.43 & 0.42 & 0.40 & 0.47 & 0.15 & 0.35 & 0.45 & - \\
\hline WOR & 0.71 & 0.75 & 0.75 & 0.56 & 0.67 & 0.59 & 0.74 & 0.64 & 0.68 & 0.67 & 0.45 & 0.61 & 0.62 & 0.56 & 0.71 & 0.73 & 0.53 & 0.40 & 0.67 & 0.56 & 0.54 & 0.65 & 0.80 \\
\hline
\end{tabular}

Source: Authors' own compilation on data from PIAAC, TiVA and other sources.

Note: WOR is the industry intensity averaged across countries (as used in the empirical specification to rank industries).

Table A10: Rank correlations of industry intensities in Managing and Communication across countries

\begin{tabular}{|c|c|c|c|c|c|c|c|c|c|c|c|c|c|c|c|c|c|c|c|c|c|c|c|}
\hline & $A \cup S$ & AUT & $\mathrm{BEL}$ & CAN & CZE & DEU & \begin{tabular}{|l|} 
DNK \\
\end{tabular} & ESP & EST & FIN & FRA' & GBR & IRL & ITA* & JPN & KOR & NLD & NOR & $\mathrm{POL}$ & RUS & SVK & SWE & USA \\
\hline AUT & 0.46 & - & & & & & & & & & & & & & & & & & & & & & \\
\hline BEL & 0.66 & 0.66 & - & & & & & & & & & & & & & & & & & & & & \\
\hline CAN & 0.65 & 0.58 & 0.72 & - & & & & & & & & & & & & & & & & & & & \\
\hline CZE & 0.61 & 0.29 & 0.39 & 0.47 & - & & & & & & & & & & & & & & & & & & \\
\hline DEU & 0.45 & 0.67 & 0.76 & 0.66 & 0.19 & - & & & & & & & & & & & & & & & & & \\
\hline \begin{tabular}{|l|} 
DNK \\
\end{tabular} & 0.45 & 0.61 & 0.62 & 0.71 & 0.38 & 0.61 & - & & & & & & & & & & & & & & & & \\
\hline ESP* & 0.43 & 0.66 & 0.60 & 0.56 & 0.20 & 0.62 & 0.56 & - & & & & & & & & & & & & & & & \\
\hline \begin{tabular}{|l|} 
EST \\
\end{tabular} & 0.52 & 0.53 & 0.37 & 0.69 & 0.44 & 0.46 & \begin{tabular}{|l|}
0.39 \\
\end{tabular} & \begin{tabular}{|l|}
0.49 \\
\end{tabular} & - & & & & & & & & & & & & & & \\
\hline FIN & 0.62 & 0.72 & 0.55 & 0.64 & 0.24 & 0.65 & 0.54 & 0.76 & 0.58 & - & & & & & & & & & & & & & \\
\hline \begin{tabular}{|l|} 
FRA $^{*}$ \\
\end{tabular} & 0.52 & 0.69 & 0.56 & 0.74 & 0.32 & 0.67 & 0.55 & 0.65 & 0.72 & 0.70 & - & & & & & & & & & & & & \\
\hline GBR & 0.54 & 0.41 & 0.35 & 0.58 & 0.51 & 0.36 & \begin{tabular}{|l|}
0.49 \\
\end{tabular} & 0.35 & 0.33 & 0.59 & 0.44 & - & & & & & & & & & & & \\
\hline IRL & 0.52 & \begin{tabular}{|l|}
0.42 \\
\end{tabular} & \begin{tabular}{|l|}
0.48 \\
\end{tabular} & 0.51 & 0.21 & 0.42 & \begin{tabular}{|l|}
0.38 \\
\end{tabular} & \begin{tabular}{|l|}
0.57 \\
\end{tabular} & 0.53 & 0.63 & \begin{tabular}{|l|}
0.40 \\
\end{tabular} & \begin{tabular}{|l|}
0.48 \\
\end{tabular} & - & & & & & & & & & & \\
\hline ITA* & 0.56 & 0.65 & 0.67 & 0.73 & 0.35 & 0.63 & 0.68 & 0.63 & 0.53 & 0.73 & 0.65 & 0.51 & 0.62 & $t$ & & & & & & & & & \\
\hline JPN & 0.27 & 0.44 & 0.49 & 0.58 & 0.35 & 0.65 & 0.52 & 0.38 & 0.37 & 0.33 & 0.55 & \begin{tabular}{|l|}
0.52 \\
\end{tabular} & 0.26 & 0.43 & & & & & & & & & \\
\hline KOR & 0.32 & 0.31 & 0.34 & 0.38 & 0.06 & 0.45 & 0.28 & \begin{tabular}{|l|}
0.47 \\
\end{tabular} & 0.41 & 0.48 & 0.40 & \begin{tabular}{|l|}
0.48 \\
\end{tabular} & 0.40 & \begin{tabular}{|l|}
0.27 \\
\end{tabular} & 0.54 & 5 & & & & & & & \\
\hline \begin{tabular}{|l|} 
NLD \\
\end{tabular} & \begin{tabular}{|l|}
0.68 \\
\end{tabular} & 0.44 & 0.54 & 0.66 & 0.22 & 0.49 & 0.50 & \begin{tabular}{|l|}
0.32 \\
\end{tabular} & 0.28 & 0.69 & \begin{tabular}{|l|}
0.51 \\
\end{tabular} & \begin{tabular}{|l|}
0.69 \\
\end{tabular} & 0.55 & \begin{tabular}{|l|}
0.78 \\
\end{tabular} & 0.38 & 0.26 & & & & & & & \\
\hline NOR & 0.57 & 0.55 & \begin{tabular}{|l|}
0.78 \\
\end{tabular} & 0.69 & 0.47 & 0.57 & \begin{tabular}{|l|}
0.60 \\
\end{tabular} & \begin{tabular}{|l|}
0.43 \\
\end{tabular} & 0.31 & 0.48 & \begin{tabular}{|l|}
0.56 \\
\end{tabular} & \begin{tabular}{|l|}
0.49 \\
\end{tabular} & 0.36 & \begin{tabular}{|l|}
0.58 \\
\end{tabular} & \begin{tabular}{|l|}
0.46 \\
\end{tabular} & 0.36 & 0.53 & - & & & & & \\
\hline POL & 0.55 & \begin{tabular}{|l|}
0.67 \\
\end{tabular} & 0.67 & 0.62 & 0.28 & 0.57 & 0.40 & 0.48 & 0.56 & 0.69 & 0.56 & 0.42 & 0.67 & \begin{tabular}{|l|}
0.63 \\
\end{tabular} & 0.35 & 0.24 & 0.62 & 0.52 & - & & & & \\
\hline RUS & 0.46 & 0.28 & 0.21 & 0.24 & 0.51 & 0.05 & 0.23 & \begin{tabular}{|l|}
0.39 \\
\end{tabular} & 0.44 & 0.39 & \begin{tabular}{|l|}
0.18 \\
\end{tabular} & 0.33 & 0.42 & 0.24 & \begin{tabular}{|l|}
0.09 \\
\end{tabular} & 0.26 & 0.15 & -0.01 & 0.31 & 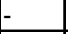 & & & \\
\hline SVK & 0.61 & 0.28 & 0.53 & 0.49 & 0.48 & 0.33 & 0.47 & 0.65 & 0.52 & \begin{tabular}{|l|}
0.39 \\
\end{tabular} & 0.36 & 0.28 & 0.62 & \begin{tabular}{|l|}
0.46 \\
\end{tabular} & 0.29 & 0.34 & 0.22 & 0.26 & 0.45 & 0.61 & - & & \\
\hline SWE & 0.31 & \begin{tabular}{|l|}
0.67 \\
\end{tabular} & 0.44 & 0.56 & 0.16 & 0.72 & \begin{tabular}{|l|}
0.37 \\
\end{tabular} & 0.49 & 0.57 & 0.72 & 0.70 & 0.47 & 0.41 & 0.50 & 0.55 & 0.49 & 0.50 & 0.43 & 0.53 & 0.14 & 0.03 & - & \\
\hline USA & 0.77 & \begin{tabular}{|l|}
0.41 \\
\end{tabular} & 0.55 & 0.60 & 0.29 & 0.42 & \begin{tabular}{|l|}
0.51 \\
\end{tabular} & 0.45 & 0.59 & 0.53 & \begin{tabular}{|l|}
0.50 \\
\end{tabular} & 0.41 & 0.51 & 0.49 & 0.33 & 0.54 & 0.47 & 0.51 & 0.56 & 0.31 & \begin{tabular}{|l|}
0.70 \\
\end{tabular} & \begin{tabular}{|l|}
0.23 \\
\end{tabular} & \\
\hline WOR & 0.77 & 0.63 & 0.73 & 0.85 & 0.50 & 0.62 & 0.71 & 0.73 & 0.72 & 0.78 & \begin{tabular}{|l|}
0.74 \\
\end{tabular} & \begin{tabular}{|l|}
0.62 \\
\end{tabular} & 0.66 & 0.77 & 0.51 & 0.51 & 0.64 & 0.67 & \begin{tabular}{|l|}
0.72 \\
\end{tabular} & 0.44 & 0.75 & \begin{tabular}{|l|}
0.50 \\
\end{tabular} & 0.82 \\
\hline
\end{tabular}

Source: Authors' own compilation on data from PIAAC, TiVA and other sources.

Note: WOR is the industry intensity averaged across countries (as used in the empirical specification to rank industries). 


\section{NOTES}

1. Self-organisation skills refer to a worker's ability to independently organise and plan his/her own work (see Table 1 for an overview).

2. $\quad$ http://www.oecd.org/skills/piaac/

3. $\quad$ https://stats.oecd.org/index.aspx?queryid=66237

4. The authors assume that skills cannot be unbundled, i.e. employers cannot unbundle workers attributes and can only choose among workers differently endowed with both skills.

5. The relative skill intensity of industries is defined on the basis of production needs. Define isoquants in the skill space as the curves showing all the combinations of inputs that yield the same levels of output, with quantitative skills measured on the $y$ axis and communication skills on the $x$ axis. An industry $i$ is said to be relatively intensive in quantitative skills compared to another industry $j$, if at the point of intersection of the isoquants in the skill space the isoquant of industry $i$ is flatter than the slope of isoquant of industry $j$.

Ohnsorge and Trefler (2007) assume that there are no distortions in product and factor markets and information asymmetries do not exist.

7. The decision to single out the skill in the denominator and call it absolute advantage is arbitrary. The authors could also have chosen the skill in the nominator, here quantitative skills, and define this as absolute advantage. For a given ratio of both skills, a larger nominator implies a larger denominator and vice versa.

8. For tractability reasons, Ohnsorge and Trefler (2007) define the variables in their model in logs. For the empirical application in their paper, they compute the correlation $\rho$ as the correlation between the log of the ratio of numeracy to literacy with log of literacy across all workers in one country.

9. See https://www.onetonline.org/

10. Following the literature on comparative advantage, in a robustness check, the authors also use the assessed cognitive skills of individuals to compute the relative intensity of industries in those skills. Results are in line with the main results of this paper and can be obtained from the authors upon request.

11. The PIAAC background questionnaire includes groups of questions that were designed to measure the use of the three assessed cognitive skills on the job. However, as discussed in Grundke et al (2017), the questions within one group often do not seem to measure the same underlying skill concept, which is why the authors decided to apply statistical factor analysis methods to construct new indicators of job-specific skill requirements. In a robustness check for this paper, the authors also compute the relative intensity of industries in the three types of cognitive skills using the original item batteries from the PIAAC background questionnaire. Results are in line with the main results of this paper and can be obtained from the authors upon request.

12. Ohnsorge and Trefler (2007) define the variables in their model in logs. For the empirical application in this study, the authors follow Ohnsorge and Trefler (2007) and compute the correlation $\rho$ as the correlation between the log of the ratio of two skills with the log of the skill in the denominator across all workers in one country.

13 As mentioned Ohnsorge and Trefler (2007) define the variables in their model in logs. This study follows Ohnsorge and Trefler (2007) and computes the country-specific relative endowment in cognitive skills (e.g. problem solving and numeracy) as the average of the (log of the) ratio of the two cognitive skills.

14. As the literature on comparative advantage assumes that the ranking of the relative intensity of industries does not change across countries (Bombardini et al. 2012, Chor 2010, Nunn 2007, Rajan and Zingales 1998), the authors computed the relative intensities of industries per country and looked at the rank 
correlation coefficients between the industry rankings of different countries to verify the robustness of this assumption (see Table A7-A10 in Appendix). The rank correlation coefficients between countries and the computed world average (WOR) are shown to be close to 0.80 , thus supporting the assumption made in the literature.

15. In a robustness check, the relative industry intensity is calculated as the average of the ratio of task-based skill A to task-based skill B (at the individual level) across countries and individuals. This leaves results unchanged. The results can be obtained from the authors upon request

16. The authors also estimate each specification using the continuous ratio as a measure of the relative industry intensities. Again, results appear robust to such changes (Table A1, A2).

17. The following note is included at the request of Turkey:

"The information in this document with reference to 'Cyprus' relates to the southern part of the Island. There is no single authority representing both Turkish and Greek Cypriot people on the Island. Turkey recognises the Turkish Republic of Northern Cyprus (TRNC). Until a lasting and equitable solution is found within the context of United Nations, Turkey shall preserve its position concerning the 'Cyprus' issue."

18. The following note is included at the request of all the European Union Member States of the OECD and the European Union:

"The Republic of Cyprus is recognized by all members of the United Nations with the exception of Turkey. The information in this document relates to the area under the effective control of the Government of the Republic of Cyprus.”

19. The list of 34 industries with corresponding ISIC Rev. 3 codes can be found on the OECD website (http://www.oecd.org/sti/ind/TiVA_2015_Industry_List.pdf).

20. Alternatively, a weighted average over all PIAAC countries has been computed, whereby each country is weighted by its share in world's total net fixed assets. Results appear robust to using either measures of the average capital intensity of industries. In estimates not reported here, this study has also used data on industries' capital intensity and relative endowment of countries in capital to labour for former years (2000, 2005, 2008, and 2009), leaving results unchanged.

21. See www.wiod.org.

22. In robustness checks, other independent variables are also taken for the year 2009 and results do not change. Using skill intensity of industries and countries' relative endowments of skilled workers for the years 2000, 2005 or 2008 does not change the results either.

23. Estimates appear robust to defining skilled workers as having completed a tertiary degree, rather than using the broader definition of secondary and tertiary education.

24. See http://www.cepii.fr/

25. This variable measures the participation of services sectors in exporting more accurately as it captures the value added created in services sector $k$ and used by manufacturing sectors as inputs for products exported to country $j$.

26. In the baseline estimation, indices ranking industries according to these computed characteristics are used (larger rank numbers indicating higher values), whereas in a robustness check the computed continuous measures enter the specification instead of the ranking indices (Appendix Table A1, A2).

27. In a robustness check, the continuous industry intensity measures are used in the specification (Appendix Table A1, A2).

28. The effect of the countries' variance of the joint skill distribution on specialisation patterns cannot be investigated empirically; because the construction of an index that would rank countries according to the variance of the joint skill distribution was not feasible. The index, if created, could only take three values, given that, for many countries, it is impossible to identify a stochastic dominance of one joint skill distribution over the other.

29. Entering the two interaction terms in distinct specifications (as in equation 1) leads to an omitted variables bias. Results can be obtained from the authors upon request. 
30. In another robustness check, the authors also compute the relative intensity of industries in the three types of cognitive skills using the original item batteries from the PIAAC background questionnaire that were designed to measure the use of the cognitive skills at the workplace (and not the new task-based skill indicators). Results are in line with the main results of this paper and can be obtained from the authors upon request.

31. For the case of using problem solving and literacy to measure skill endowments, the estimated coefficients for the other independent variables as well as other regression statistics can be found in Appendix Table A3.

32. The finance and insurance industry ranks $7^{\text {th }}$ in the relative intensity index for Self-Organisation vs. Management and Communication, the industry manufacturing and equipment ranks $25^{\text {th }}$; see Table A5 Appendix.

33. For the case of using problem solving to measure the residual skill dispersion, the estimated coefficients for the other independent variables as well as other regression statistics can be found in Appendix Table A4.

34. The residual skill dispersions computed using literacy and numeracy differ across countries (Figure 3), which explains why the coefficients in Table 4 are different for numeracy and literacy. 


\section{REFERENCES}

Asuyama, Yoko (2012), "Skill Distribution and Comparative Advantage: A Comparison of China and India”, World Development, Vol. 40(5), pp. 956-969.

Bombardini, Matilde, Giovanni Gallipoli and German Pupato (2014), "Unobservable skill dispersion and comparative advantage”, Journal of International Economics, Vol. 92(2), pp. 317-329.

Bombardini, Matilde, Giovanni Gallipoli and German Pupato (2012), "Skill Dispersion and Trade Flows", American Economic Review, Vol. 102(5), pp. 2327-2348.

Bombardini, Matilde, Giovanni Gallipoli and German Pupato (2009), "Skill Dispersion and Trade Flows", NBER Working Papers, No. 15097, National Bureau of Economic Research, Inc.

Bougheas, Spiros and Riezman, Raymond (2007), “Trade and the distribution of human capital”, Journal of International Economics, Vol. 73(2), pp. 421-433.

Chor, David (2010), “Unpacking sources of comparative advantage: A quantitative approach”, Journal of International Economics, Vol. 82(2), pp. 152-167.

Cingano, Federico and Paolo Pinotti (2016), "Trust, firm organization, and the pattern of comparative advantage”, Journal of International Economics, Vol. 100, pp. 1-13.

Costinot, Arnaud (2009), “On the origins of comparative advantage”, Journal of International Economics, Vol. 77, pp. 255-264.

Cuñat, Alejandro and Marc J. Melitz (2010), “A Many-Country, Many-Good Model of Labor Market Rigidities as a Source of Comparative Advantage", Journal of the European Economic Association, Vol. 8 (2-3), pp. 434-441.

Davis, Donald R. and David E. Weinstein (2001), “An Account of Global Factor Trade”, American Economic Review, Vol. 91(5), pp. 1423-1453.

Eaton, Jonathan and Samuel Kortum (2002), “Technology, Geography and Trade”, Econometrica, Vol. 70(5), pp. 1741-1779.

Egger, Peter, Kathryn G. Marshall and Eric O'N. Fisher (2011), "Empirical foundations for the resurrection of Heckscher-Ohlin theory”, International Review of Economics and Finance, Vol. 20(2), pp. 146156.

Essaji, Azim (2008), “Technical regulations and specialization in international trade”, Journal of International Economics, Vol. 76(2), pp. 166-176.

Grossmann, G. (2013), “Heterogenous Workers and International Trade”, NBER Working Paper, No. 18788, National Bureau of Economic Research, Inc.

Grossman, Gene M. (2004), “The Distribution of Talent and the Pattern and Consequences of International Trade”, Journal of Political Economy, Vol. 112(1), pp. 209-239.

Grossman, Gene M. and Giovanni Maggi (2000), “Diversity and Trade”, American Economic Review, Vol. 90(5), pp. 1255-1275.

Grundke, Robert, Margarita Kalamova, Francois Keslair, Stephanie Jamet, and Mariagrazia Squicciarini (2017), "Skills and Global Value Chains: A Characterisation", OECD Science, Technology and Innovation Working Papers, forthcoming, OECD Publishing, Paris. 
Grundke, Robert, Margarita Kalamova, Stephanie Jamet, and Mariagrazia Squicciarini (2016), "Skills and Global Value Chains: A First Characterisation”, Mimeo.

Heckscher, Eli Filip, and Bertil Gotthard Ohlin (1991), "Heckscher-Ohlin trade theory”, The MIT Press, Cambridge.

Johnson, Robert C. (2014), "Five Facts about Value-Added Exports and Implications for Macroeconomics and Trade Research”, Journal of Economic Perspectives, Vol. 28(2), pp. 119-142.

Kremer, Michael (1993), “The O-Ring Theory of Economic Development”, Quarterly Journal of Economics, Vol. 108 (3), pp. 551-575.

Krishna, Pravin, Jennifer P. Poole, and Mine Zeynep Senses (2012), “ Trade, Labor Market Frictions, and Residual Wage Inequality across Worker Groups”, American Economic Review: Papers \& Proceedings 2012, Vol. 102(3), pp. 417-423.

Levchenko, Andrei A. (2007), “Institutional Quality and International Trade”, Review of Economic Studies, 74(3), pp. 791-819.

Manova, Kalina (2008), “Credit constraints, equity market liberalizations and international trade”, Journal of International Economics, pp. 76(1), 33-47.

Morrow, Peter M. (2010), "Ricardian-Heckscher-Ohlin comparative advantage: Theory and evidence”, Journal of International Economics, Vol. 82(2), pp. 137-151.

Nunn, Nathan (2007), "Relationship-Specificity, Incomplete Contracts, and the Pattern of Trade", The Quarterly Journal of Economics, Vol. 122(2), pp. 569-600.

OECD (2013), “Technical Report of the Survey of Adult Skills (PIAAC)”, OECD Publishing, Paris, http://www.oecd.org/skills/piaac/_Technical\%20Report_17OCT13.pdf.

Ohnsorge, Franziska and Daniel Trefler (2007), "Sorting It Out: International Trade with Heterogeneous Worker”, Journal of Political Economy, Vol. 115(5), pp. 868-892.

Rajan, Raghuram G. and Luigi Zingales (1998), "Financial dependence and growth”, American Economic Review, Vol. 88(3), pp. 559-586.

Romalis, John (2004), "Factor Proportions and the Structure of Commodity Trade", American Economic Review, Vol. 94(1), pp. 67-97.

Tang, Heiwai (2012), “Labor market institutions, firm-specific skills, and trade patterns”, Journal of International Economics, Vol. 87, pp. 337-351.

Timmer, Marcel P., Bart Los, Robert Stehrer and Gaaitzen J. de Vries (2013), "Fragmentation, incomes and jobs: an analysis of European competitiveness”, Economic Policy, Vol. 28(76), pp. 613-661.

Trefler, Daniel (1995), “The Case of the Missing Trade and Other Mysteries”, American Economic Review, Vol. 85(5), pp. 1029-1046.

Trefler, Daniel (1993), “International Factor Price Differences: Leontief Was Right!”, Journal of Political Economy, Vol. 101(6), pp. 961-987. 